\section{A) Check for updates}

Cite this: Mater. Adv., 2020, 1,1038

Received 5th May 2020,

Accepted 23rd June 2020

DOI: $10.1039 / \mathrm{d} 0 \mathrm{ma00278j}$

rsc.li/materials-advances

\title{
Recent advances, design guidelines, and prospects of flexible organic/inorganic thermoelectric composites
}

\author{
Qinghui Jiang, (D) $\dagger^{*^{a}}$ Junyou Yang, (D) *a Peter Hing ${ }^{b}$ and Haitao Ye (D) $\uparrow^{\mathrm{b}}$
}

\begin{abstract}
Thermoelectrics can recover waste heat, environmental heat or heats from different sources and convert it to electricity. Inorganic or metal thermoelectrics have higher $Z T$ values and efficiency; however, they are also expensive, rigid or have poor mechanical properties, and they contain toxic or rare elements. Organic thermoelectrics have low cost, flexible mechanical properties, and facile and rapid formation; however, they have very low $Z T$ values and efficiency compared with inorganic materials. Organic-inorganic composite thermoelectrics can benefit from both properties and are also extremely competitive for commercial applications. This review will focus on flexible organic-inorganic composite thermoelectrics and devices as well as their challenges.
\end{abstract}

\section{Introduction}

Many serious energy problems and environmental pollution issues are associated with rapid industrial development worldwide. The low carbon manufacturing concept was proposed to reduce $\mathrm{CO}_{2}$ emissions, energy costs, and reliance on fossil fuels. In power plants, steel and iron factories, car engines and everyday electronics, a large proportion of energy from fossil fuels is lost worldwide as wasted heat (about $60 \%$ of the energy generated by fuels worldwide). Most of this energy is low-heat: waste heat below $100{ }^{\circ} \mathrm{C}$ accounts for $42 \%$, and waste heat between $100{ }^{\circ} \mathrm{C}$ and $200{ }^{\circ} \mathrm{C}$ accounts for $22 \% .{ }^{1-3}$ The development of clean and environmentally friendly new energy conversion materials has drawn considerable attention to recycle waste heat and achieve cost-effective energy conservation. Meanwhile, micro-sensors and intelligent equipment for human health monitoring, intelligent human-machine interaction, the Internet of Things, cloud platforms, and other technologies are urgently needed to obtain continuous electricity from the environment. Thermoelectric materials can realize thermoelectric generation and cooling by utilizing the Seebeck effect and Peltier effect. With no mechanical moving parts, no noxious emission, light weight, lack of pollution and compact structures, thermoelectric materials have broad application prospects in this field as a clean energy form and as

\footnotetext{
${ }^{a}$ School of Materials Science and Engineering, Huazhong University of Science and Technology, Wuhan, China.E-mail: qhjiang@hust.edu.cn, jyyang@hust.edu.cn

${ }^{b}$ School of Engineering, University of Leicester, University Road, Leicester LE1 7RH, UK. E-mail: haitao.ye@leicester.ac.uk

$\dagger$ Q. Jiang and H. Ye contributed equally.
}

chips/laser coolers that can realize direct conversion between waste heat/ambient temperature differences and energy. ${ }^{4}$

For wider commercial applications, thermoelectric materials need a higher figure of merit (ZT), which requires a higher Seebeck coefficient, higher electrical conductivity, and lower thermal conductivity. Over the past 10-15 years, new materials design ideas (mainly involving nanostructures), new promising bulk compounds, and novel synthesis and processing methods have fuelled much research activity in thermoelectrics. These efforts have led to the discovery of novel inorganic materials with $Z T$ values larger than 1: these include thin-film superlattices, nanostructures, and semiconductors with engineered band gaps. ${ }^{5-7}$ Unfortunately, many of these systems require the use of toxic or rare elements and often have very expensive synthesis procedures. Current commercial materials contain large amounts of rare elements, such as tellurium or toxic $\mathrm{Pb}$ elements (for example, $\mathrm{Bi}_{2} \mathrm{Te}_{3}$ or $\mathrm{PbTe}$ ) with $Z T$ values near 1.0-1.5; this prohibits future scale-up. ${ }^{8}$ Moreover, the current manufacture of thermoelectric generators (TEGs) requires sawing of TE materials, which results in substantial amounts of expensive raw-material waste. At present, for widespread application of TEGs as a waste heat recovery technology, the following scientific hurdles must be overcome: (1) synthesis of low-cost, environmentally benign and nontoxic high performance thermoelectric materials, ${ }^{9,10}$ and (2) fabrication of shapeengineerable device/systems for practical application.

Organic molecules and polymer semiconductors have emerged as new thermoelectric materials. These materials can be tailored "on demand" by means of chemistry to afford complex systems that can perform proper electric and thermal transport properties. Thermoelectric polymers have the characteristics of light weight, 
low cost, flexible mechanical properties, facile processing, abundant resources and environmental friendliness. Organic small molecules (OSMs) have the advantages of easy purification, no batch-to-batch variation, well-defined molecular and electronic structures, and intermolecular packing properties. Thus, OSMs have become a new frontier research area of molecular functional materials. ${ }^{11}$ However, they have rather low $Z T$ values and efficiency compared with inorganic materials. Compositing is proven to be effective in enhancing thermoelectric performance, and organic-inorganic thermoelectric composites can have the benefits of both properties; thus, they are extremely competitive for commercial applications. This review will focus on organicinorganic composite thermoelectrics and devices as well as their future challenges.

\section{Scientific mechanism of organic/ inorganic thermoelectric composites}

\subsection{Percolation theory}

Percolation theory was initially adopted to analyze physical phenomena near the onset of global connectivity in disordered systems. Geometric percolation transition (the percolation threshold) is defined as follows: the particles of a minor phase (i.e., fillers) come into contact with each other, and a continuous cluster extends throughout the system. This percolation theory is very effective to account for the physical properties of heterogeneous multicomponents (or phases). ${ }^{12}$ When the content is near this threshold, dramatic nonlinear changes occur in the physical properties of the composites, including their electrical or thermal conductivity, as shown in Fig. 1. The transport properties of the system near the conductiveinsulating transition can be described by percolation equations with power laws of $\left(\sigma \propto\left(f_{\mathrm{c}}-f_{\mathrm{V}}\right)^{-s}\right)$ for $f_{\mathrm{V}}<f_{\mathrm{c}}$, and $\sigma \propto\left(f_{\mathrm{V}}-f_{\mathrm{c}}\right)^{t}$ for $f_{\mathrm{V}}>f_{\mathrm{c}}$, where $f_{\mathrm{V}}$ is the volumetric fraction of the conductive

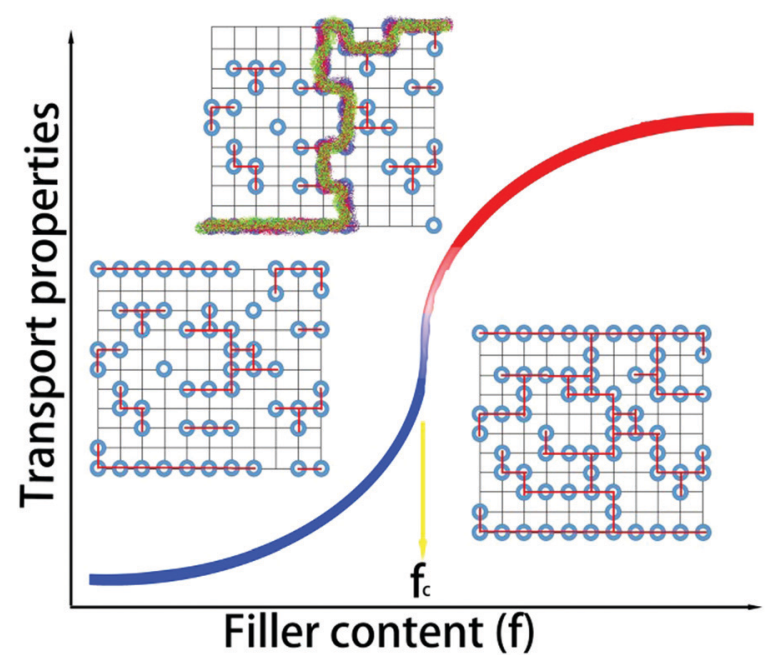

Fig. 1 Percolation theory and nonlinear changes in the transport properties of composites near the percolation threshold $f_{\mathrm{c}}$ (dashed blue line). The insets show the geometric phase transition of fillers (denoted by dark spots) in the microstructures of the composites near percolation. second phase, $f_{\mathrm{c}}$ is the percolation threshold, $t$ is the critical exponent in the conducting region, and $s$ is the critical exponent in the insulating region.

Atomic-scale or molecular percolation phenomena of electric and thermal conductivity were already found in inorganic and organic thermoelectric materials with quasi-disordered structures. ${ }^{13-15}$ For example, digenite $\mathrm{Cu}_{x} \mathrm{~S}$ exhibits fast-ion conduction with liquid-like mobility. At high temperature, copper ions are randomly located between the closely packed sulphur ions and jump to other positions via unoccupied interstices. The copper vacancies (i.e. unoccupied interstices) can be regarded as the conductive media in a percolation system. In one sulphur hexagonal unit cell $\left(6-\mathrm{Cu}_{x} \mathrm{~S}\right)$, there are 6 sulphur atoms and 18 interstices. In a simple rigid model, the content of conductive minor phase $\left(f_{\mathrm{V}}\right)$ can be calculated as $(18-6 x) / 24$. Near the percolation threshold value $\left(f_{\mathrm{c}} \sim 0.3\right)$ in the conductive region, a $60 \%$ enhancement of the $Z T$ value can be obtained. ${ }^{16}$ In $\mathrm{WTe}_{2} / \mathrm{CoSb}_{3}$ inorganic composites, the locally percolated highly conductive $\mathrm{WTe}_{2}$ pellets improved the electrical conductivity of the composite, and the pronounced bipolar peak of pristine $\mathrm{CoSb}_{3}$ was quickly suppressed upon the addition of $\mathrm{WTe}_{2}$. As a result, the power factor was markedly enhanced by up to 59 times that of the pristine $\mathrm{CoSb}_{3}$ upon compositing. ${ }^{17}$ Horta et al. prepared polyaniline-poly(vinylacetate) (PANI-PVAc) organic nanocomposites via latex technology. ${ }^{18}$ The relationship between the electrical properties (piezoresistive, thermoresistive and thermoelectric behaviour) and the PANIPVAc ratio complied well with the percolation model related to morphological and structural changes. The composites with 10-30 wt\% PANI had suitable electrical conductivities and beneficial thermostability of the polymer matrix for sensor applications. This effect plays a key role in organic/inorganic composites and guides the design and optimization of material compositions, microstructures and performance. ${ }^{19,20}$

\subsection{Grain boundaries and interface effects}

Three thermoelectric parameters, namely electric conductivity, Seebeck coefficient and thermal conductivity, are interdependent on each other. Much effort has been made to decouple these parameters, such as phonon engineering and band engineering. ${ }^{21-23}$ Since the lattice thermal conductivity can be relatively dependent, phonon engineering is popular to improve the $Z T$ values of thermoelectrics. The introduction of atomic-scale lattice disorder, nanoscale precipitates and mesoscale grain boundaries can effectively scatter phonons with different mean free paths, which can lead to a decrease of the lattice thermal conductivity and enhance the $Z T$ values. $^{24}$

Andrei et al. studied the size dependence of electrical conductivity in PEDOT:PSS with different layers fabricated via spin coating on glass plates. The electrical conductivity significantly depended on the thickness of the layers. As indicated by AFM, UV-vis, Raman, and XPS measurements, this behaviour could be attributed to a combination of factors at two different scales: percolation between the grains and reorganization of the conjugated chains. ${ }^{25}$ Based on similar mechanisms, most inorganic/organic thermoelectric nanocomposites are fabricated 
in order to obtain lower thermal conductivity and higher $Z T$ values near the critical condition of percolation. However, the interfaces between the organic and inorganic phases are not clear, which normally leads to high resistivity and weakens the expected effects. $^{26,27}$

\subsection{Superlattice effects/energy filter effects}

Normally, the coupling of electrical and thermal transport leads to difficulty in individually tailoring the phonon properties without deterioration of the electronic transport. In 1993, LD Hicks et al. ${ }^{28}$ proposed that the power factor of a thermoelectric superlattice can be increased from an enhanced density of states near the Fermi energy according to the quantum confinement effect. Another phonon-blocking/electrontransmitting superlattice can utilize the acoustic mismatch between the different layers and obviously reduce the thermal conductivity of the lattice. Scientists subsequently constructed inorganic/inorganic superlattices, such as $\mathrm{PbSe}_{0.98} \mathrm{Te}_{0.02} / \mathrm{PbTe}$ and $\mathrm{Bi}_{2} \mathrm{Te}_{3} / \mathrm{Sb}_{2} \mathrm{Te}_{3}$ superlattices. ${ }^{29}$ Using these effects, $Z T$ values of 1.5-2.0 near room temperature were obtained. Experiments confirmed that the structure would lead to a significant increase in the Seebeck coefficient and a linear decrease in thermal conductivity with increasing thickness of the superlattice.

Organic/inorganic nanostructures with superlattices can potentially show hybrid properties synergistically derived from both the host and the guest, such as micro-scale composites with the percolation phenomenon. Meanwhile, the interinsertion of (conjugated) polymers and layered inorganic materials can afford novel electrical and thermal properties. ${ }^{30}$ For example, M. G. Kanatzidis et al. ${ }^{31}$ fabricated a nanoscale molecular composite via the encapsulation of polyaniline (PANI) in $\mathrm{MoS}_{2}$, leading to unusual charge-transport properties. C. L. Wan et al. ${ }^{32,33}$ fabricated inorganic/organic $\operatorname{TiS}_{2}\left[(\mathrm{HA})_{x^{-}}\right.$ $\left.(\mathrm{DMSO})_{w}\right]$ superlattices via electrochemical intercalation and solvent exchange. These hybrid inorganic/organic superlattices possessed a high electronic power factor from the inorganic component $\mathrm{TiS}_{2}$. The coupling between the inorganic and organic layers plays a key role in the scattering of phonon transport. As a result of the significant reduction in the

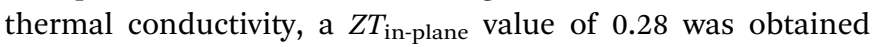
in $\mathrm{TiS}_{2}\left[(\mathrm{HA})_{0.08}\left(\mathrm{H}_{2} \mathrm{O}\right)_{0.22}(\mathrm{DMSO})_{0.03}\right]$ near $100{ }^{\circ} \mathrm{C}$, as shown in Fig. 2.

With the successful exfoliation of monolayer graphene, twodimensional materials (such as hexagonal boron nitride, $\mathrm{MoS}_{2}$, and phosphene) have drawn strong attention. It has been found that the transport barrier of electrons can be regulated via changing the number of layers of two-dimensional materials in the heterojunction based on van der Waals heterojunctions, such as graphene/phosphene/graphene, graphene/BN/graphene, and silicone/transition metal sulphides. ${ }^{34-36}$ As a result, the thermal conductivity in the plane direction of the vertical heterojunction will be much lower than that of the interface bonded by covalent bonds. ${ }^{37}$ This indicates that the construction of van der Waals heterojunctions is an effective strategy to optimize the thermoelectric performance of materials. Because the cross-linking of organic molecular layers can effectively
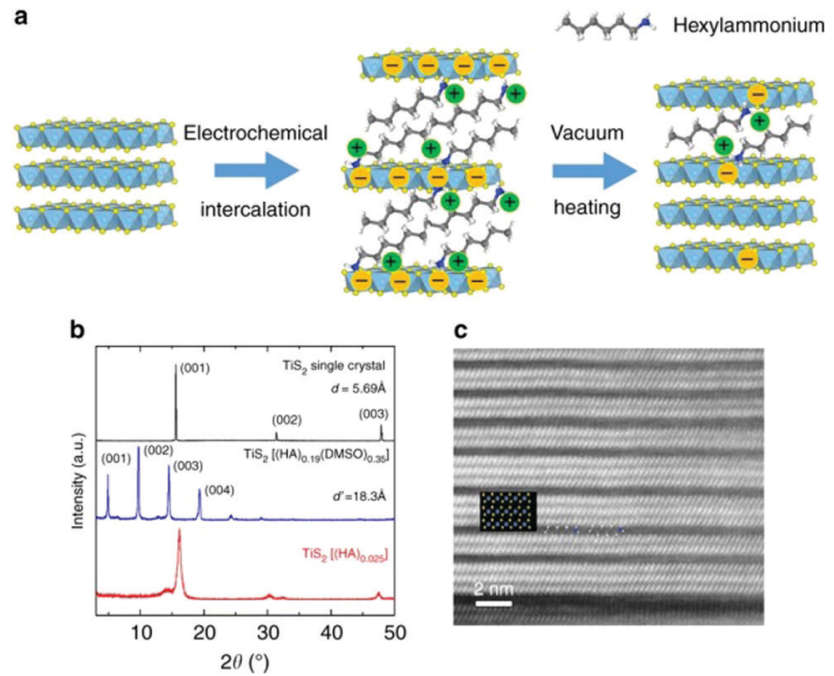

Fig. 2 (a) Schematic of the electrochemical intercalation process. (b) XRD patterns of $\mathrm{TiS}_{2}$ single crystal and its related superlattice structures. (c) Magnified STEM image of $\mathrm{TiS}_{2}(\mathrm{HA})_{0.025}$. (Reproduced from ref. 33 with permission from Nature Communication.).

decouple the interaction between atomic layers, organic/ inorganic van der Waals heterojunction superlattices have more important research significance. In 2018, Wang et al. ${ }^{36}$ successfully prepared organic/inorganic superlattices such as $\mathrm{BP} / \mathrm{CTAB}$ (hexadecyltrimethylammonium bromide), SnSe/CTAB and $\mathrm{Bi}_{2} \mathrm{Se}_{3}$ by electrochemical molecular embedding. These general synthesis routes and ideas can be extended to thermoelectric research and lead to extraordinary improvement of $Z T$ values in the future.

The energy filter effect is partly classified as a superlattice effect, which can explain the increase of the Seebeck coefficient in 0-3 type thermoelectric nanocomposites. For example, an n-type $\mathrm{Ag}_{2} \mathrm{Se} / \mathrm{Ag} / \mathrm{CuAgSe}$ composite film has an ultrahigh power factor of $2231.5 \mu \mathrm{W} \mathrm{m}{ }^{-1} \mathrm{~K}^{-2}$ at $300 \mathrm{~K}$. There are energy barriers near the $\mathrm{Ag}_{2} \mathrm{Se} / \mathrm{Ag}, \mathrm{CuAgSe} / \mathrm{Ag}$ and $\mathrm{Ag}_{2} \mathrm{Se} / \mathrm{CuAgSe}$ interfaces. Fig. 3 shows the equilibrium band diagrams of $\mathrm{Ag} / \mathrm{Ag}_{2} \mathrm{Se}$, $\mathrm{CuAgSe} / \mathrm{Ag}_{2} \mathrm{Se}$ and $\mathrm{Ag} / \mathrm{CuAgSe}$. The blend band gap between the two semiconductors and metallic Ag NPs forms a Schottky barrier. In the composite, low-energy carriers are blocked, while high-energy carriers can jump across the interfaces. This leads to the coexistence of high carrier concentration and a decent

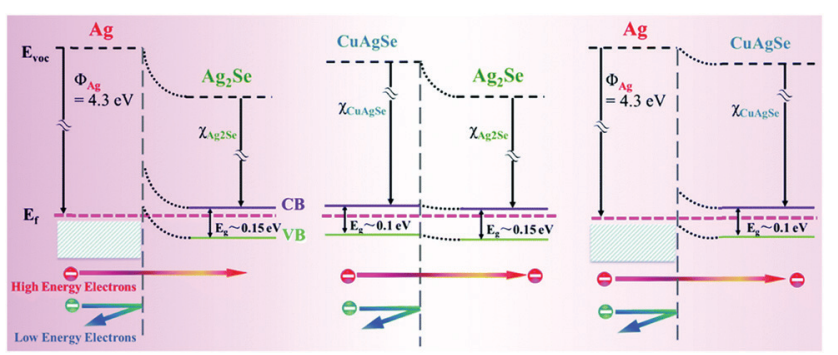

Fig. 3 Equilibrium band diagrams for $\mathrm{Ag} / \mathrm{Ag}_{2} \mathrm{Se}, \mathrm{CuAgSe} / \mathrm{Ag}_{2} \mathrm{Se}$ and $\mathrm{Ag} /$ CuAgSe. $^{38}$ 
Seebeck coefficient, which results in an ultrahigh power factor. $^{38}$

\section{Fabrication techniques and future challenges}

The fabrication of thermoelectric composite films or bulk materials with excellent electrical transport properties remains a major bottleneck for high-performance flexible TE materials and devices. Currently, several fabrication methods are used, as discussed in the following sections.

\subsection{Electro-spinning technique}

The electro-spinning technique is used to fabricate ultra-fine fibres with high surface-to-volume ratios and controllable compositions starting from molten polymers or a solution. The electro-spun fibres have a homogeneous chemical composition and uniform particle size distribution. This technique is based on the application of an electric field to a drop of fluid on the tip of a spinneret. As shown in Fig. 4a, a syringe pump is used to eject the solution at a controllable speed through the needle, and the collector is placed near the tip. A high voltage is applied between the tip and the collector, which leads to evaporation of the solvent and the formation of continuous fibres. ${ }^{39,40}$ To date, electro-spun polymer nanofibres have been successfully investigated in biomedical applications and nanocatalysis due to their high surface-to-volume ratio, low density, and flexibility. Dalton et al. used electro-spinning to fabricate p-type and n-type carbon fibres from mixtures of lignin and PAN. ${ }^{41}$ Meanwhile, inorganic fibres, such as $\mathrm{NaCo}_{2} \mathrm{O}_{4}{ }^{42}$ $\mathrm{Mg}_{2} \mathrm{Si}^{43}$ and PbTe (Fig. 4b), ${ }^{44}$ were successfully fabricated with some flexibility. In thermoelectric fibres, grain boundaries and interfaces can also scatter phonons, thereby lowering the thermal conductivity and optimizing the transport properties of the fibres. However, it is still challenging to obtain fibre

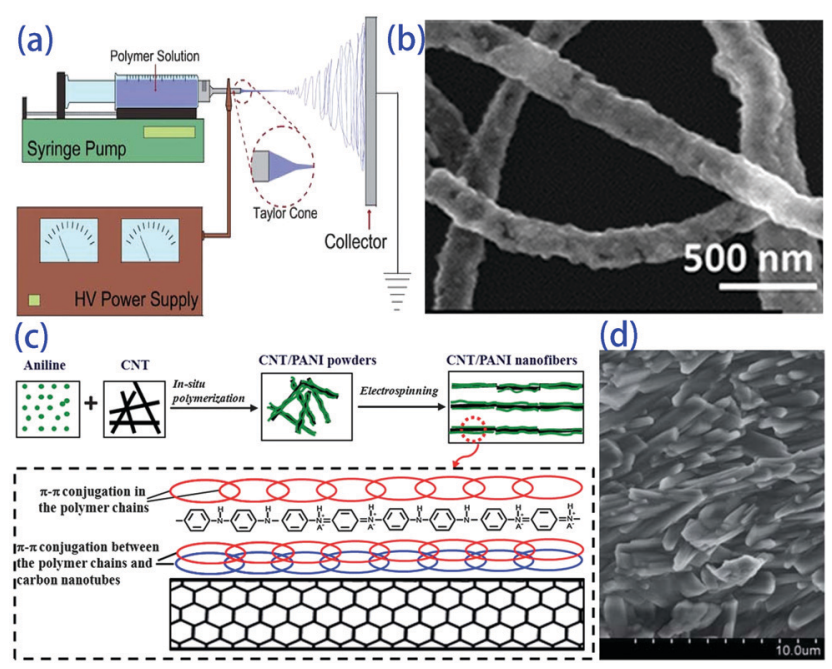

Fig. 4 (a) Scheme of a conventional electrospinning setup, ${ }^{39}$ (b) electrospun hollow PbTe nanofibers, ${ }^{44}$ (c) schematic of the formation mechanism and (d) SEM image of CNT/PANI nanofibers. ${ }^{45}$ composites with good thermoelectric properties. Wang et al. prepared carbon nanotube and polyaniline (PANI) composite nanofibres by in situ polymerization combined with electrospinning processes. Carbon nanotubes and PANI backbone chains are oriented along the fibre axis due to strong chemical interactions, as shown in Fig. $3 c$ and d. High orientation of the PANI backbone chains reduces the $\pi-\pi$ conjugated defects, boosts the effective degree of electron delocalization and therefore heightens the carrier mobility in PANI, which results in doubled improvement of the power factor in the orientation direction. ${ }^{45}$ This indicates that the electro-spinning process provides an effective route to design a flexible composite with high thermoelectric performance through high ordering of the backbone chain structure. Highly flexible textiles containing n- and p-junctions prepared by this process can harvest environmental heat in the desirable through-thickness direction, and a power output of up to $8.6 \mathrm{~W} \mathrm{~m}^{-2}$ is obtained when the temperature difference is $200{ }^{\circ} \mathrm{C}^{46}$

\subsection{Hot pressing or spark plasma sintering}

During the hot pressing process, a uniaxial pressure is applied while heating a powder compact which is placed in a graphite or alloy mould. This process was developed and applied earlier in powder metallurgy to fabricate high-temperature alloys and ceramics with high density under relatively low sintering temperatures. ${ }^{47}$ Recently, hot pressing has become a relatively mature technique for the preparation of thermoelectric nanocomposites. ${ }^{38,48-50}$

Because of the thermoplasticity of the polymer matrix, most dense organic-inorganic composites can be fabricated via a simple homemade hot pressing device. J. Kim et al. ${ }^{51}$ prepared n-type carbon bucky paper with carbon nanotubes and a PVDF composite via hot pressing at $60{ }^{\circ} \mathrm{C}$ in $6 \mathrm{MPa}$ for $3 \mathrm{~min}$. $\mathrm{Bi}_{0.5} \mathrm{Sb}_{1.5} \mathrm{Te}_{3}$ /epoxy thick films with high orientation were prepared via brush-printing and hot pressing on polyimide substrates. $^{52}$ For a prototype flexible TE cooling device with $\mathrm{Bi}_{0.5} \mathrm{Sb}_{1.5} \mathrm{Te}_{3} /$ epoxy thick films, the stable temperature difference of the prototype device reached $6{ }^{\circ} \mathrm{C}$ under a working current of $0.06 \mathrm{~A}$.

Spark plasma sintering (SPS) is an efficient sintering method that allows rapid consolidation at comparatively low temperatures, ${ }^{16,53-55}$ and it is especially suitable for fabricating thermoelectric composite materials. ${ }^{56,57}$ Ge et al. fabricated a PEDOT:PSS/Cu $\mathrm{Cu}_{2} \mathrm{SnS}_{3}$ nanocomposite polymer bulk via spark plasma sintering (SPS) at $100{ }^{\circ} \mathrm{C}$. The polymer powder transformed into a homogeneous polymer bulk after SPS (the process is shown in Fig. 5), and this product showed much better properties than a sample processed using a cold press. The sample with $33 \mathrm{wt} \%$ nanoparticles showed the highest $Z T$ of the samples tested, with a value of 0.04 at $45{ }^{\circ} \mathrm{C}$; this is 20 times higher than the 0.002 value of a pristine PEDOT:PSS bulk sample. $^{56}$

\subsection{Solution processing}

Solution processing methods are highly suitable for the preparation of thermoelectric materials with organic matrices. 
(a)

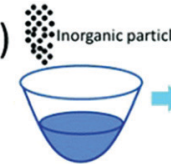

$$
\text { PEDOT:PSS solution Ultra sonic mixing }
$$

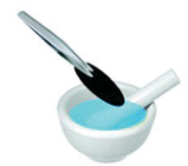

Grounded in Liquid Nitrogen

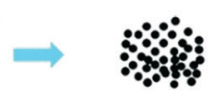

Polymer composite powder

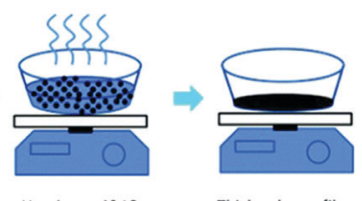

Thick polymer film

SPS at $100^{\circ} \mathrm{C}$ $\longrightarrow$

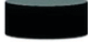

(b)

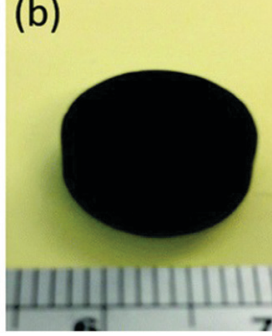
(c)
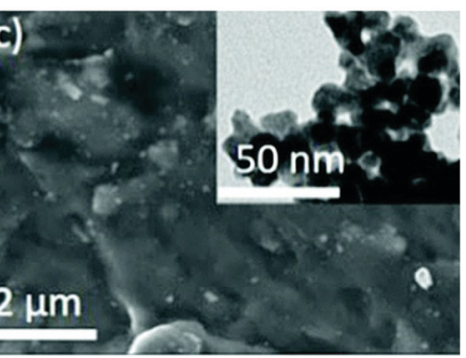

Polymer composite bulk

Fig. 5 (a) Process used to synthesize bulk polymers. (b) Photograph of a polymer bulk sample after applying SPS. (c) CSS polymer bulk with an inset showing a TEM image of $\mathrm{Cu}_{2} \mathrm{SnSe}_{3}$ nanoparticles. (Reproduced from ref. 56 with permission from The Royal Society of Chemistry.).

Among them, hydrothermal synthesis is an effective method to prepare inorganic fillers without aggregation. ${ }^{58}$ The inorganic filler solution is blended with organic thermoelectrics and finally dropped on a pre-cleaned or vacuum-filtered glass slide, followed by rapid drying under vacuum to form an organicinorganic thermoelectric composite film. ${ }^{59}$ For example, Miao et al. ${ }^{60}$ used a hydrothermal method to obtain a reductive graphene material (RGO) with high electrical conductivity; they then prepared an $\mathrm{RGO} / \mathrm{Te}$ nanowire bilayer composite film on a glass fiber filter substrate by drop coating. The results showed that the film has a maximum power factor of $80 \mu \mathrm{W}\left(\mathrm{m} \mathrm{K}^{2}\right)^{-1}$. Lin et $a l .{ }^{61}$ added cuprous selenide powder to mixed solvent at room temperature and stirred the solution for $10 \mathrm{~min}$; by this process, $\mathrm{Cu}_{2} \mathrm{Se}$ ink could be directly obtained. A uniform film was prepared on a sapphire substrate by a simple spin coating process, and its power factor reached $0.62 \mathrm{~mW}\left(\mathrm{~m} \mathrm{~K}^{2}\right)^{-1}$. After repeated bending 1000 times, about $90 \%$ of the thermoelectric performance could be maintained.

\subsection{Paste processing or silk-screen printing}

As a traditional printing method, screen printing is regarded as a manufacturing method for rapidly and efficiently fabricating thermoelectric thin films and thermoelectric devices because of its low cost, simple operation, scalable production, and even curved surface printing. ${ }^{62,63}$

Generally, the preparation of the organic-inorganic composite paste for screen printing is accomplished by subjecting previously prepared organic and inorganic components to solution treatment. In order to achieve a better deposition effect on the substrate during printing, the organic-inorganic composite paste has basic viscosity requirements. Other challenges

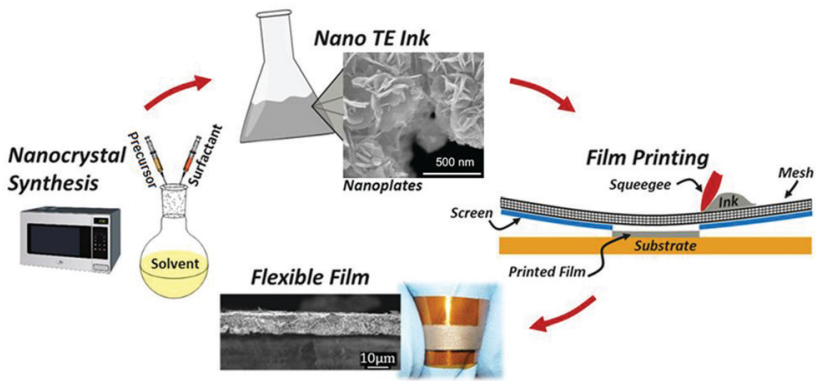

Fig. 6 Schematic of the overall fabrication process of flexible thermoelectric films, including nanocrystal synthesis, nano-ink processing, screen printing of thermoelectric films on a flexible substrate, and sintered flexible films. (Reproduced from ref. 63 with permission from Scientific Reports.).

include anti-oxidation during printing and curing and posttreatment of the composite paste after screen printing. Many types of thermoelectric composite films have been fabricated by screen printing, such as $\mathrm{Bi}_{2} \mathrm{Te}_{3}$ and PbTe-based materials. ${ }^{64-67}$ Wang et al. obtained a PANI/Te composite film by combining Te nanorods with conductive polymer polyaniline (PANI) via screen printing, and a ZT value of 0.22 was obtained at $110{ }^{\circ} \mathrm{C}$. The prototype device with 10 legs of PANI/Te-Ag branches had a maximum output voltage and output power of $29.9 \mathrm{mV}$ and $0.73 \mu \mathrm{W}$ respectively at $\Delta T=40{ }^{\circ} \mathrm{C}$. ${ }^{68}$ Varghese et al. fabricated flexible $\mathrm{Bi}_{2} \mathrm{Te}_{3}$ films and devices by screen printing. The paste was synthesized via a microwave-stimulated wet-chemical method. Thermoelectric films were printed onto a polyimide substrate followed by cold compaction and annealing (the process is shown in Fig. 6). The thermoelectric device with the printed films has a power density of $4 \mathrm{~mW} \mathrm{~cm}^{-2}$ at $\Delta T=60^{\circ} \mathrm{C}$. As a highly scalable and low-cost process, screen printing technology has great potential applications to fabricate flexible thermoelectric energy harvesting and cooling devices.

\subsection{Layer deposition technique}

The basic principle of traditional deposition technology, in short, is to deposit foreign matter on the surface of a substrate to form a composite film. During the deposition processes of thermoelectric organic-inorganic composites, organic materials are usually used as substrates or working electrodes, and inorganic materials are deposited on the surface of the organic materials to form 2-2 composite systems. Additionally, OSM materials can be deposited layer by layer with inorganic materials to fabricate superlattice structures. ${ }^{30,69,70}$ Although many layer deposition techniques can be used to deposit inorganic materials, such as pulsed laser deposition and physical vapour deposition, there are two traditional technologies to realize commercial layer-by-layer deposition for organic/inorganic composites, as follows.

3.5.1 Electrochemical deposition technology. Electrochemical deposition is a technique in which positive and negative ions in the electrolyte solution migrate under the action of an electric field and redox reactions occur on the electrode to generate films. This method is suitable for industrial production due to its low investment cost and high efficiency, and it has received attention for fabricating thermoelectric devices. ${ }^{71-73}$ 
Because electrochemical deposition can only occur on conductive substrates, a feasible choice to prepare organic-inorganic composite films is to electrochemically deposit inorganic thermoelectric materials on organic intrinsically conductive polymers (ICP) for use as a working electrode. Culebras et al. prepared thin Te/PEDOT films by depositing Te on the PEDOT working electrode by a simple electrochemical deposition method. ${ }^{74}$ The Seebeck coefficient of the film increased from $9 \mu \mathrm{V} \mathrm{K} \mathrm{K}^{-1}$ to $230 \mu \mathrm{V} \mathrm{K}^{-1}$ after deposition, leading to a higher power factor $\left(320 \mu \mathrm{W}\left(\mathrm{m} \mathrm{K}^{2}\right)^{-1}\right)$. However, there was a significant increase in the electric resistivity due to the high porosity of the Te polycrystalline film. It will be very challenging in the future to increase the electric conductivity of films obtained by electrochemical deposition.

3.5.2 ALD/MLD. Similar to conventional chemical vapor deposition (CVD), atomic layer deposition can deposit substances on substrates layer by layer with single atomic thickness. The material reactions during atomic layer deposition exhibit the characteristics of sequential, self-limiting surface reactions; therefore, this technique can be used to achieve atomic-scale thickness control and conformal deposition. ${ }^{75-78}$ At present, the preparation of inorganic thermoelectric materials by $\mathrm{ALD}$, including $\mathrm{Bi}_{2} \mathrm{Te}_{3}$, $\mathrm{Sb}_{2} \mathrm{Te}_{3}, \mathrm{Bi}_{2} \mathrm{Se}_{3}, \mathrm{ZnO}$ and $\mathrm{TiO}_{2}$, has been reported in the literature. ${ }^{79-82}$ Because the ALD process can be conducted under steady voltage and low temperature, there are fewer restrictions on the substrate, and this technique may be highly competitive in the field of flexible material preparation ${ }^{83-85}$ and in the incorporation of inorganic thermoelectric materials into textile materials to expand their use in wearable flexible thermoelectric materials. ${ }^{86}$

Molecular layer deposition (MLD) is another technique similar to ALD that uses sequential, self-limiting reactions to deposit thin films in molecular units. The combination of ALD and MLD technology allows us to alternately deposit metal oxides and organics on a substrate to produce a homogeneous organic-inorganic superlattice material rather than simply depositing inorganic materials on organic substrates, as shown in Fig. 7. The oxide-organic interface may scatter more phonons or lead to confinement effects, which enhances the thermoelectric properties of the materials. ${ }^{87}$ Karttunen et al. used ALD/MLD to fabricate thermoelectric ZnO-organic superlattice thin films on cotton textile substrates; the films had excellent flexibility and exhibited lower thermal conductivity than the pristine $\mathrm{ZnO}$ film. ${ }^{88}$ It is foreseeable that ALD and MLD technologies will play important roles in the field of flexible thermoelectric materials and devices.

\subsection{Inkjet printing}

In recent years, inkjet printing technology has been introduced into the manufacture of electronic devices (OLED, PCB, etc.) due to its unique advantages of no-contact, additive and digitized processes. The simple spin-spray process can be also included in this category; it is one of the most effective strategies for the rapid development of uniform thermoelectric films with relatively complex structures. ${ }^{89}$

According to different working principles, inkjet printing technology can be divided into two types: continuous inkjet

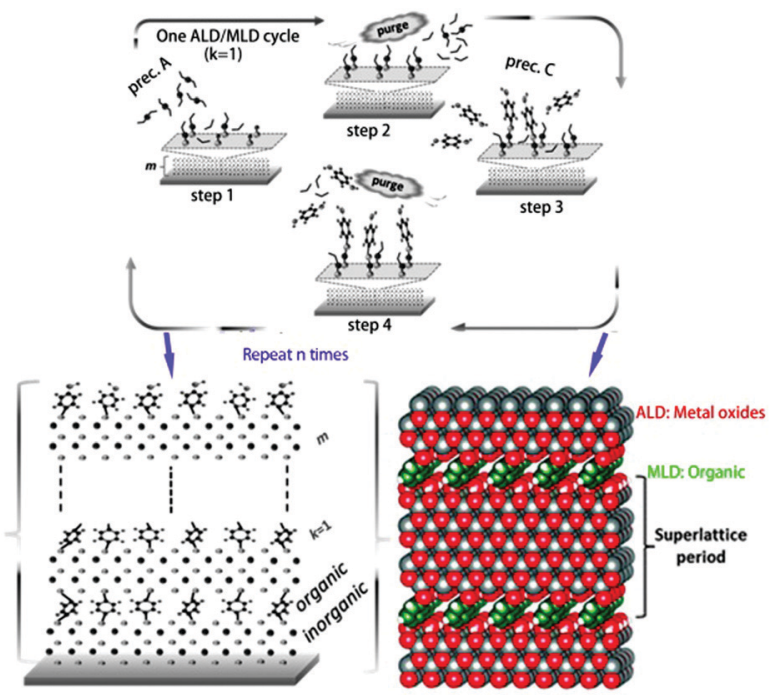

Fig. 7 ALD/MLD cycle schematic of the growth of superlattice structures: (1) pulse the metal precursor (e.g. diethylzinc) on the surface, (2) purge the excess precursor and byproduct molecules with inert gas, (3) pulse the organic precursor, and (4) purge the excess organic precursor and byproduct molecules again. A superlattice film of organic/inorganic layers with controlled thickness is fabricated via repeating the ALD/MLD cycle. (Reproduced from ref. 87 with permission from The Royal Society of Chemistry.)

printing and drop-on-demand inkjet printing. The latter has gradually become the mainstream in the market. At present, drop-on-demand inkjet technology mainly includes two types, namely thermal inkjet technology and piezoelectric inkjet technology. Thermal inkjet technology generates vapor bubbles inside the ink by rapidly heating the ink (generally heating above the boiling point of the ink); this is more suitable for water-based ink than organic solvents because of the need to heat and evaporate the ink. ${ }^{90}$

Utilizing the inverse piezoelectric effect, the piezo inkjet printer shrinks the ink through a piezoelectric element controlled by an electrical signal to cause the ink to be squeezed away from the nozzle and finally ejected onto the substrate to form a pattern. This technology reduces energy consumption, prolongs the service life of the machine, and overcomes the limitations of the ink materials; therefore, it is a promising approach after overcoming the challenges of thermoelectric inks. ${ }^{90-93}$ While ensuring the good thermoelectric performance of the ink, it is also necessary to take into account the printability of the ink, which poses a great challenge for the design of thermoelectric composite material systems and is also key to the realization of inkjet printing of high-quality thermoelectric materials. This is because (1) the inherent complexity of the thermoelectric composite system leads to dynamic changes in the thermoelectric properties and fluid properties of the ink, caused by the type and proportion of composite; (2) in order to meet the printable and post-treatment requirements of thermoelectric inks, they often contain additives such as surfactants, binders, thickeners, and stabilizers, which undoubtedly increases the complexity of the ink system. ${ }^{94,95}$ 
There have been some reports on the inkjet printing of thermoelectric materials, including $\mathrm{Bi}_{2} \mathrm{Te}_{3}$, graphene, carbon nanotubes and polymers, ${ }^{96-101}$ which mostly focus on regulation of the printing performance of thermoelectric inks. Chen et al. ${ }^{99}$ prepared $\mathrm{Bi}_{2} \mathrm{Te}_{3}$ thermoelectric nanowires and then dispersed them in deionized water in an ultrasonic bath to form a jettable ink, which was finally printed onto a glass substrate. The Seebeck coefficient of the film was about $140 \mu \mathrm{V} \mathrm{K}^{-1}$, similar to that of bulk $\mathrm{Bi}_{2} \mathrm{Te}_{3}$. Kato et al. ${ }^{102}$ studied the preparation of a coatable ink of $\mathrm{Bi}_{0.4} \mathrm{Sb}_{1.6} \mathrm{Te}_{3}$, PEDOT:PSS and an organic additive (PAA). Chen et al. inkjet-printed $\mathrm{Bi}_{2} \mathrm{Te}_{3}$ and $\mathrm{Bi}_{0.5} \mathrm{Sb}_{1.5} \mathrm{Te}_{3}$ nanowires as inks to onto polyimide to form a highly flexible TEG. After annealing at $450{ }^{\circ} \mathrm{C}$, maximum power factors of $180 \mu \mathrm{W}$ $\left(\mathrm{m} \mathrm{K}^{2}\right)^{-1}$ and $110 \mu \mathrm{W}\left(\mathrm{m} \mathrm{K}^{2}\right)^{-1}$ were obtained for the $\mathrm{Bi}_{2} \mathrm{Te}_{3}$ and $\mathrm{Bi}_{0.5} \mathrm{Sb}_{1.5} \mathrm{Te}_{3}$ films. ${ }^{103}$ The power of the generator could reach $\sim 130 \mathrm{nW}$ at $\Delta T=32{ }^{\circ} \mathrm{C}$, and it maintained its performance even after 50 bending experiments (with a tight radius of curvature of $\sim 10 \mathrm{~mm}$ ), as shown in Fig. 8. In future, if thermoelectric inks with long-term stability, suitable fluid properties and excellent thermoelectric properties can be obtained, it will be possible to produce low-cost, high-efficiency, miniaturized and expandable flexible TEGs by inkjet printing.

\subsection{D printing}

As an "additive manufacturing technology", in recent years, 3D printing technology has received increasing attention worldwide; this includes fused deposition molding (FDM), stereolithography apparatus (SLA), laminated object manufacturing (LOM) and selective laser sintering (SLS). Due to its advantages of rapid prototyping, high material utilization, printability of complex entities and flexible product design, 3D printing has been used to fabricate thermoelectric devices. He et al. fabricated a thermoelectric organic-inorganic composite material with ultra-low thermal conductivity and a $Z T$ value of up to 0.12 by preparing a $\mathrm{Bi}_{0.5} \mathrm{Sb}_{1.5} \mathrm{Te}_{3} /$ photosensitizer composite in combination with SLA technology. ${ }^{104} \mathrm{Kim}$ et al. prepared

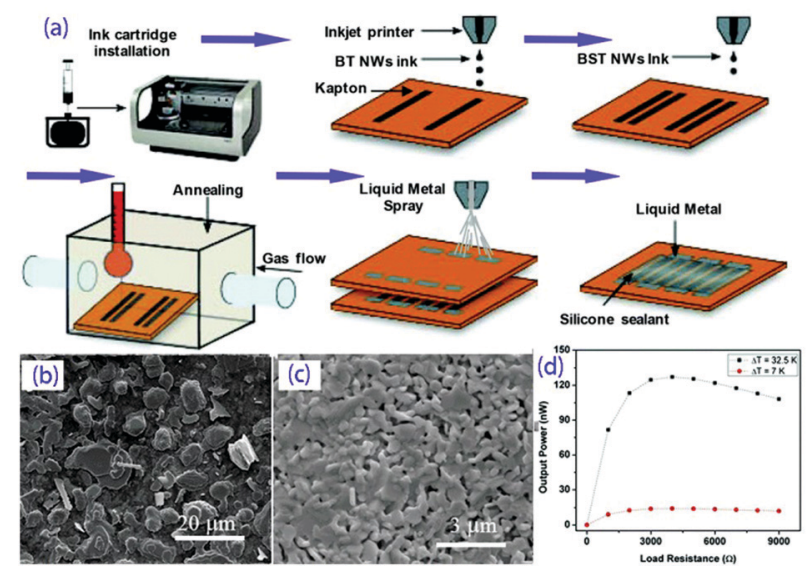

Fig. 8 (a) Fabrication schematic for the development of the inkjet-printed TEG device; SEM micrographs of the printed BST50 (b) and BT50 (c) nanowires annealed at $450{ }^{\circ} \mathrm{C}$ for $10 \mathrm{~min}$; (d) output power of the printed TEG as a function of load resistance. (Reproduced from ref. 103 with permission from The Royal Society of Chemistry.). a $\mathrm{Bi}_{2} \mathrm{Te}_{3}$-based thermoelectric ink using $\mathrm{Sb}_{2} \mathrm{Te}_{3}$ chalcogenidometallate ions as a binder and fabricated thermoelectric devices using an extrusion-based 3D printer built in-house. ${ }^{105}$ The TE materials they prepared with different shapes obtained $Z T$ values of 0.6 (N-type) and 0.9 (P-type). The cylindrical TEG, which was fabricated using a $3 \mathrm{D}$ printing method, achieved a power density of $1.4 \mathrm{~mW} \mathrm{~cm} \mathrm{~cm}^{-2}$ at $40{ }^{\circ} \mathrm{C}$. Wang et al. prepared a thermoelectric composite wire for FDM-based 3D printing by extrusion synthesis using polylactic acid (PLA) as a matrix and $\mathrm{Bi}_{0.5} \mathrm{Sb}_{1.5} \mathrm{Te}_{3}$ as the filler. ${ }^{106}$ The thermoelectric properties and the flexibility of the composite wires could be controlled by tailoring the content of the fillers and the matrix. These results indicate that $3 \mathrm{D}$ printing has great potential in the field of thermoelectric composite materials and has the opportunity to be applied to the rapid production of flexible thermoelectric materials and devices. ${ }^{107}$

\section{Chalcogenide-based composites}

Chalcogenide-based thermoelectric materials have better thermoelectric properties, especially higher Seebeck coefficients; these include $\mathrm{Bi}_{2} \mathrm{Te}_{3}$-based thermoelectric materials. When $\mathrm{Bi}_{2} \mathrm{Te}_{3}$ is combined with organic thermoelectric materials such as poly(3,4-ethylenedioxythiophene) polystyrene sulfonate (PEDOT: PSS) and polylactic acid, it shows good thermoelectric properties and can have the advantages of mechanical flexibility and low price at the same time. Generally, a composite material composed of two components according to the mixture model has thermoelectric properties between those of its two single components. A $\pi-\pi$ conjugate interaction between the carbon nanotubes/polymer will lead to novel phenomena for the hybrid model. However, the weakening of this interaction and the instability of the operations have led to some different results between research groups.

\section{1 $\mathrm{Bi}_{2} \mathrm{Te}_{3}$-based composite}

$\mathrm{Bi}_{2} \mathrm{Te}_{3}$-based thermoelectric materials exhibit similar work functions to other organic thermoelectric materials, such as PEDOT:PSS, polylactic acid, poly(3-hexylthiophene) (P3HT) and epoxy resin; the low-energy carriers are scattered due to the interface between the inorganic nanoparticles and the organic matrix. This scattering effect enables organic-inorganic composite thermoelectric materials to obtain higher Seebeck coefficients without substantially lowering their electrical conductivity; therefore, they show superior performance.

4.1.1 0-3 type $\mathbf{B i}_{2} \mathbf{T e}_{3}$-based composites. There are many types of $\mathrm{Bi}_{2} \mathrm{Te}_{3}$-based thermoelectric composites; however, most of them are combined with conductive polymers such as PEDOT: PSS, P3HT, and polylactic acid (PLA). PEDOT:PSS is an organic thermoelectric material with good thermoelectric properties, and its similar work function to that of $\mathrm{Bi}_{2} \mathrm{Te}_{3}$ is beneficial to strongly scatter low-energy carriers at the organicinorganic interface, thereby obtaining a higher Seebeck coefficient. As a result, PEDOT:PSS is the first choice as the polymer matrix of $\mathrm{Bi}_{2} \mathrm{Te}_{3}$ and organic composite materials. 
Table 1 A summary of the low-temperature-range thermoelectric properties of selected typical polymer composites

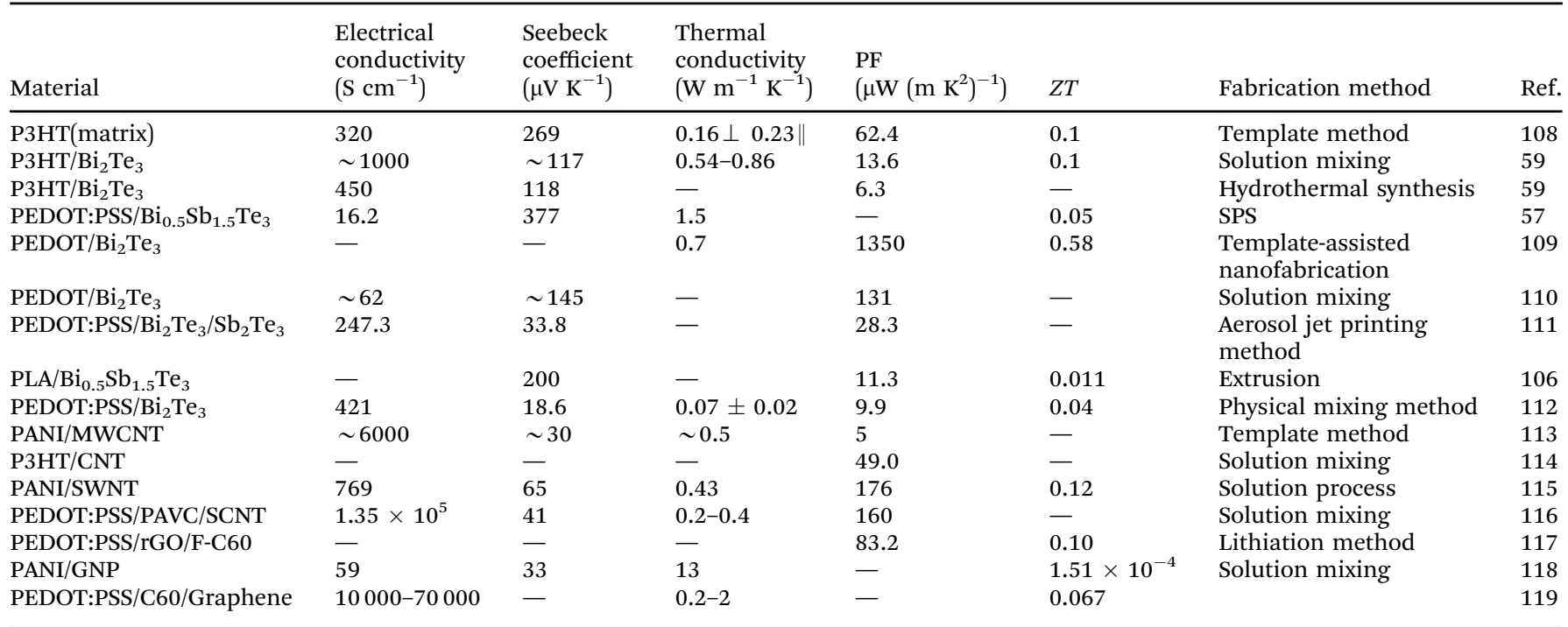

Recent studies on $\mathrm{Bi}_{2} \mathrm{Te}_{3}$-based composite thermoelectric materials are shown in Table 1 . Wang et al. ${ }^{106}$ proposed the preparation of a composite filament with polylactic acid as the matrix and $\mathrm{Bi}_{0.5} \mathrm{Sb}_{1.5} \mathrm{Te}_{3}$ (BST) as a filler by extrusion molding, and they finally obtained a $Z T$ value of 0.011 at room temperature. Wei et $a .^{57}$ reported the preparation of PEDOT:PSS/ $\mathrm{Bi}_{0.5} \mathrm{Sb}_{1.5} \mathrm{Te}_{3}$ bulk composites by SPS sintering; with $20 \mathrm{wt} \%$ ethylene glycol and $20 \mathrm{wt} \% \mathrm{Bi}_{0.5} \mathrm{Sb}_{1.5} \mathrm{Te}_{3}$ doping in PEDOT:PSS, the $Z T$ value of the sample was upgraded by two orders of magnitude, eventually reaching 0.05 . He et al. ${ }^{59}$ studied the synthesis of $\mathrm{Bi}_{2} \mathrm{Te}_{3}$ nanowires by a hydrothermal method and then combined them with $\mathrm{P} 3 \mathrm{HT}$ to obtain organic-inorganic nanocomposites that showed a higher power factor of $13.6 \mu \mathrm{W}\left(\mathrm{m} \mathrm{K}^{2}\right)^{-1}$ compared with that of pure P3HT $\left(3.9 \mu \mathrm{W}\left(\mathrm{m} \mathrm{K}^{2}\right)^{-1}\right)$ prepared by the same method.

4.1.2 Quasi-two-dimensional composites. For bulk thermoelectric materials, their coupled thermoelectric parameters limit their efficiency and application; meanwhile, two-dimensional and quasi-two-dimensional composites have a positive effect on decoupling the thermoelectric parameters. Surface deformation can greatly increase the state density and thus enhance the conductivity. Surface disorder and numerous interfaces are beneficial for strongly scattering phonons to reduce thermal conductivity, and 2D electron gas and energy filtering effects can improve the Seebeck coefficient and ultimately improve the material properties. ${ }^{120-122}$ Two-dimensional and quasi-twodimensional chalcogenide-based composites are the most studied; they have a wide range of applications, such as flexible wearables. $\operatorname{Sun}^{120}$ et al. reported that the thermoelectric figure of a $\mathrm{Bi}_{2} \mathrm{Se}_{3}$ composite film (single layer of atomic thickness) was eight times higher than that of the bulk material. We et al. ${ }^{123}$ reported the use of screen printing to prepare inorganic thermoelectric and organic conductive polymer composite films that showed good flexibility; this work also provides a promising development path for the application of flexible highperformance thermoelectrics. Wang et al. ${ }^{109}$ fabricated flexible
PEDOT hybrids with patterned $\mathrm{Bi}_{2} \mathrm{Te}_{3}$ nanophases via nanosphere lithography. The size and spacing of the nanophases were precisely tuned from tens to hundreds of nanometers (as shown in Fig. 9). The high electrical conductivity of the doped PEDOT, high Seebeck coefficient of thermally evaporated $\mathrm{Bi}_{2} \mathrm{Te}_{3}$ and carrier-filtering effect at the nanoscaled PEDOT- $\mathrm{Bi}_{2} \mathrm{Te}_{3}$ interface led to higher power factors. With more interfacial phonon scattering, the $Z T$ value could reach 0.58 at room temperature.

4.1.3 Other chalcogenide-based composites. In addition to the most studied $\mathrm{Bi}_{2} \mathrm{Te}_{3}$-based thermoelectric materials, other chalcogenide compounds have been used to fabricate thermoelectric composites. Although their $Z T$ values are lower than those of $\mathrm{Bi}_{2} \mathrm{Te}_{3}$-based materials, these materials have the advantages of lower cost and non-toxicity, and they are promising and competitive in future commercial applications. Dun ${ }^{124}$ et al.

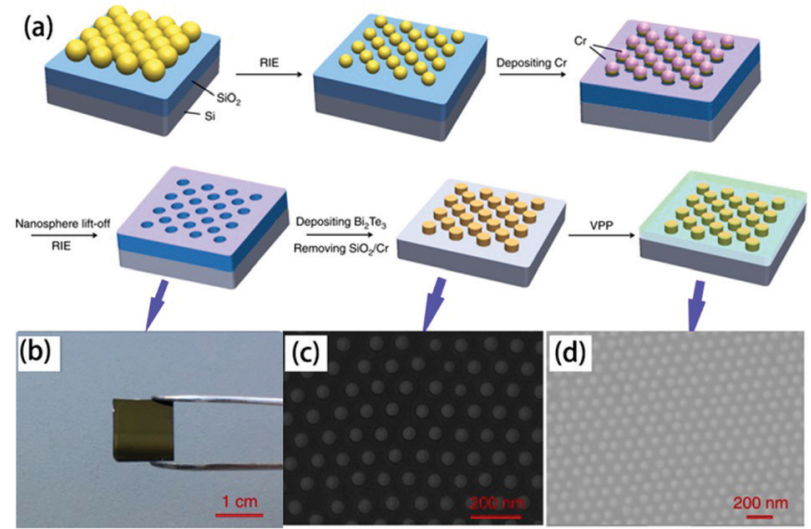

Fig. 9 (a) Scheme of the fabrication of the organic/inorganic hybrid film via by nanosphere lithography, (b) digital photograph of closely packed monolayer PS nanospheres on a $\mathrm{SiO}_{2} / \mathrm{Si}$ substrate after etching, SEM image of (c) $\mathrm{Bi}_{2} \mathrm{Te}_{3}$ nanoparticle arrays prepared by using $100 \mathrm{~nm}$ PS nanospheres as patterns and (d) PEDOT/Bi $2 \mathrm{Te}_{3}(100)$ hybrid films. ${ }^{109}$ 
reported $\mathrm{Cu}_{0.1} \mathrm{Bi}_{2} \mathrm{Se}_{3}$ nanoplatelet/PVDF composites with high flexibility that showed one of the highest thermoelectric figures for an n-type thermoelectric film at room temperature, reaching 0.10. Ju et al. ${ }^{125}$ prepared tin selenide nanosheets by hydrothermal lithium intercalation combined with an exfoliation process and then fabricated SnSe NS/PEDOT:PSS composites. When the content of SnSe NS reached $20 \%$, its thermoelectric figure of merit could reach 0.32 . Wan et al. ${ }^{32}$ reported that they obtained a hybrid superlattice of $\mathrm{TiS}_{2} /\left[(\text { hexylammonium })_{x^{-}}\right.$ $\left.\left(\mathrm{H}_{2} \mathrm{O}\right)_{y}(\mathrm{DMSO})_{z}\right]$, which shows a $Z T$ value of 0.28 at $373 \mathrm{~K}$ due to its high power factor and ultra-low thermal conductivity. ${ }^{32}$

\section{Carbon-based composites}

In addition to traditional inorganic thermoelectric materials, nanostructured carbon materials such as carbon nanotubes and graphene are often used as fillers for composite thermoelectric materials because carbon nanotubes and graphene have high electrical conductivity, which improves the electrical conductivity of the composite. Moreover, because the carbonbased nanomaterial has a conjugated $\pi-\pi$ structure and a large specific surface area, which facilitates intimate contact with the conductive polymer, the interfacial effect on the phonon scattering is enhanced; therefore, the composite has lower thermal conductivity. Finally, the synergy between this carbon material and the conductive polymer endows the polymer with good thermoelectric properties. For example, Muller et al. ${ }^{126}$ found that the thermoelectric properties of polymer materials can be improved by combining conductive polymer materials with CNTs. The thermoelectric properties of carbon-based composites can be improved not only by controlling the level of polymer doping, but also by changing the processing process. ${ }^{127}$ Therefore, these composite materials have received extensive attention, and carbon nanotubes are the most commonly used fillers in thermoelectric composite materials.

\subsection{Carbon-nanotube-based composites}

Carbon nanotubes are considered to be a type of tubular graphite molecule and have received increasing attention. They also show good thermoelectric performance, with $Z T$ 0.4-0.8 at 1000 K. ${ }^{128}$ For example, C. J. An et al. studied the doping characteristics of directly spun carbon nanotube webs and found that treatment with benzyl viologen resulted in a maximum power factor of $3103 \mu \mathrm{W} \mathrm{m}{ }^{-1} \mathrm{~K}^{-2}$, similar to those of $\mathrm{Bi}_{2} \mathrm{Te}_{3}$ compounds. ${ }^{129}$ Due to the high strength, high electrical conductivity and other multi-functional properties of carbon nanotubes, a great deal of research has been performed to enhance the performance of polymer matrices by using the nanotubes as a nanofiller. ${ }^{130-132}$ Currently, high performance carbon nanotube/polymer composites still face many challenges, such as the limitations of the dispersion, content and connectivity of the carbon nanotubes in the polymer matrix. ${ }^{133}$

$\mathrm{Wu}$ et al. ${ }^{134}$ proposed a new "layer-by-layer deposition" method for the preparation of CNT/PVA composite fibers. The in situ mixing of two complex components at the molecular level promotes the dispersion of carbon nanotubes and PVA to infiltrate into the fibers efficiently, eventually increasing the strength from 50 to $1255 \mathrm{MPa}$ and the conductivity from 0 to $2000 \mathrm{~S} \mathrm{~cm}^{-1}$. Because the grown carbon nanotubes have different diameters, the influences of the carbon nanotube diameter and mass fraction on the properties of the composite have been widely studied. Qu et al. ${ }^{114}$ prepared CNT/P3HT composite films by solution mixing, in which the diameter of the carbon nanotubes was between $8 \mathrm{~nm}$ and $>50 \mathrm{~nm}$. When the diameter of the carbon nanotubes was $<8 \mathrm{~nm}$ and the mass fraction was $5 \%$, the composite film had a maximum power factor of $50 \mu \mathrm{W}\left(\mathrm{m} \mathrm{K}^{2}\right)^{-1}$. Yao et al. ${ }^{115}$ prepared SWCNT/PANI films with different SWCNT contents using a simple solution process; the maximum Seebeck coefficient and resistivity reached $65 \mu \mathrm{V} \mathrm{K} \mathrm{K}^{-1}$ and $769 \mathrm{~S} \mathrm{~cm}^{-1}$, respectively, which are several times higher than those of pure PANI and carbon nanotube films, and the final power factor and $Z T$ values reached $176 \mu \mathrm{W}\left(\mathrm{m} \mathrm{K}^{2}\right)^{-1}$ and 0.12 , respectively, which are the highest values obtained for current organic-inorganic composite thermoelectric materials.

Kim et al. used single-walled carbon nanotube (SWCNT)/ poly(vinylidene fluoride) (PVDF) pastes to prepare composite fibers via a wet-spinning process. The dispersion state of the SWCNTs may affect the mechanical properties of the composite fibers. After optimization, the power factors of the p- and n-type SWCNT/PVDF composite fibers were 380 and $290 \mu \mathrm{W}\left(\mathrm{m} \mathrm{K}^{2}\right)^{-1}$, respectively. The 16 p-type and 15 n-type fibers (diameter $\sim 140 \mu \mathrm{m}$ and length $1.5 \mathrm{~cm}$ ) in series were attached on a paper substrate using silver paste to fabricate a TEG; the maximum output power of the device was $0.61 \mu \mathrm{W}$ at $\Delta T=10{ }^{\circ} \mathrm{C}$ (as shown in Fig. 10). ${ }^{135}$

In the past decade, the thermoelectric properties of only a few organic small molecule (OSM) materials have been studied in detail, such as porphyrin, ${ }^{136}$ bis-(ethylenedithio)tetrathiafulvalene (BEDT-TTF), ${ }^{137}$ 2-[4,5-(1,2-cyclohexylenedithio)-1,3dithiol-2-ylidene]-5-[4,5-bis(methylthio)-1,3-dithiol-2-ylidene]1,3,4,6-tetrathiapentalene (ChTM-TTP), ${ }^{138}$ thiophene-diketopyrrolopyrrole-based quinoidal small molecules (TDPPQ), ${ }^{139}$

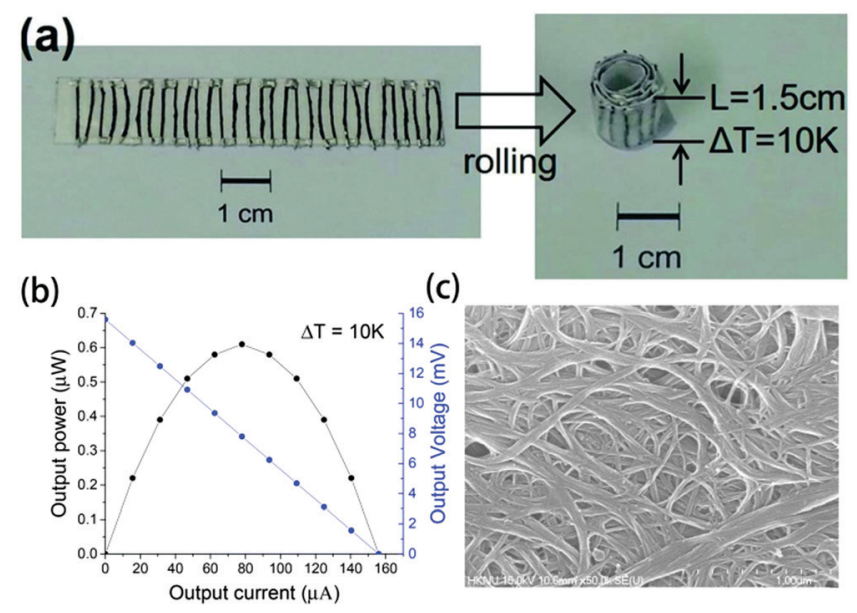

Fig. 10 (a) Photograph and (b) output power-current and output voltagecurrent curves of the TEG with SWCNT/PVDF composite fibers. (c) SEM image of PEI(2wt\%)-treated SWCNT/PVDF fibers (50wt\%). (Reproduced from ref. 135 with permission from The Royal Society of Chemistry.). 
(dipyrrolo[3,4-c]pyrrole-1,4-diylidene)bis(thieno[3,2-b]thiophene) (DPPTT) ${ }^{140}$ and bis(ethylenedithio)tetrathiafulvalene (BEDTTTF). ${ }^{141}$ They have lower power factors (maximum power factor $\left.100-200 \mu \mathrm{W} \mathrm{m}^{-1} \mathrm{~K}^{-2}\right)^{139,140}$ compared with inorganic thermoelectric compounds. Therefore, in addition to the superlattice structures discussed in section 2.3, OSM materials are often chosen as fillers or coatings of thermoelectric composites in which carbon nanotubes are an additional phase. ${ }^{136,142}$ Yao et al. fabricated copper phthalocyanine (CuPc)/singlewalled carbon nanotube (SWCNT) p-type composites by high energy ball milling and cold pressing. ${ }^{143}$ A large number of CuPc-SWCNT nano-interfaces in the composites lead to strong donor-acceptor and $\pi-\pi$ conjugation interactions and endow CuPc with highly ordered face-on packing, which leads to an increase of the carrier concentration and carrier mobility. After optimization, CuPc/SWCNT composites showed a maximum power factor of about $70.1 \mu \mathrm{W}\left(\mathrm{m} \mathrm{K}^{2}\right)^{-1}$.

Wang et al. prepared a series of OSMs and SWCNTs composites by a drop-casting process and solution-phase or vapour-phase doping, ${ }^{144,145}$ as shown in Fig. 11a. The interfacial doping of the thermoelectric composite films with a vacuum-deposited organic acceptor, 7,7,8,8-tetracyanoquinodimethane (TCNQ), leads to the formation of charge-transfer complex crystals at the interface, resulting in increased carrier mobility. As shown in Fig. 11b and c, less interruption to the lattice structure and controlled charge transfer between these phases leads to a higher power factor of $284 \mu \mathrm{W}\left(\mathrm{m} \mathrm{K}^{2}\right)^{-1}$ at room temperature. ${ }^{145}$

\subsection{Graphene-based composites}

Although pure organic thermoelectric materials have good thermoelectric properties, their properties are still far poorer than those of inorganic thermoelectric materials. If graphene with high electrical and mechanical properties is introduced into an organic thermoelectric material, it is expected that the low thermal conductivity of the organic thermoelectric material
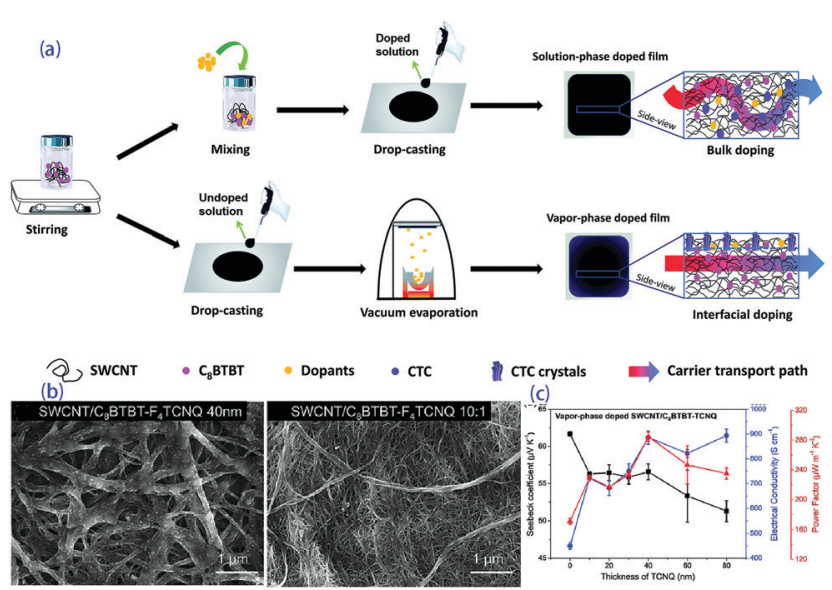

Fig. 11 (a) Fabrication processes of the composite films by bulk doping or interfacial doping, (b) SEM pictures of an SWCNT/C ${ }_{8} B T B T-F_{4} T C N Q$ film obtained with a vapor-phase process and an SWCNT/C8BTBT-F4TCNQ film obtained with a solution-phase process, and (c) the transport properties of vapor-phase doped SWCNT/C 8 BTBT-TCNQ with different thicknesses of TCNQ. ${ }^{145}$ will combine with the high electrical conductivity of graphene to afford better performance. Also, when graphene is uniformly dispersed in the polymer matrix, it has a higher ability to enhance the thermoelectric properties of composites than carbon nanotubes because graphene has a larger surface area and stronger $\pi-\pi$ interactions with the same weight. According to the literature, ${ }^{146-148}$ when graphite is uniformly distributed in the polymer matrix, graphene can increase the interface area 2-10 times more than the equivalent mass of carbon nanotubes; a 10-fold increase in $Z T$ value can be observed after the addition of 2 to $3 \mathrm{wt} \%$ of graphene into the PEDOT:PSS matrix, which is much higher than that of the carbon nanotube-based composite material. Graphene is also used as a template in a polymer matrix for the purpose of stretching a polymer chain (such as PAIN) to enhance its carrier mobility and increase its conductivity without reducing its thermal power. Xiang et al. ${ }^{118}$ synthesized a paper-like GNP-PAIN complex by in situ polymerization of single molecule aniline in the presence of GNP, and its $Z T$ value shows two orders of magnitude of improvement compared to pure PAIN and GNP. Recently, fullerene has also been used to enhance the performance of graphene-based composite thermoelectric materials. In this system, rGO is non-covalently functionalized by fullerene and then incorporated into the PEDOT:PSS matrix. The conductivity can be increased by graphene, while fullerene can increase the Seebeck coefficient and does not greatly improve the thermal conductivity. Due to this synergistic effect, the thermoelectric figure can reach 0.067 , which is an order of magnitude higher than that of any single component-filled thermoelectric polymer. ${ }^{119}$ Zhang et al. ${ }^{117}$ successfully synthesized $\mathrm{rGO} / \mathrm{F}-\mathrm{C}_{60}$ nanohybrids using a lithiation method, in which rGO is noncovalently functionalized by F- $\mathrm{C}_{60}$ so that $\mathrm{F}^{-\mathrm{C}_{60}}$ can regulate the $\mathrm{HOMO}$ and work function of $\mathrm{rGO}$. The prepared $\mathrm{rGO} / \mathrm{F}-\mathrm{C}_{60}$ nanohybrids were incorporated into the organic conductive polymer PEDOT:PSS, and low-energy carriers were scattered by the Schottky barrier at the interface between $\mathrm{rGO} / \mathrm{F}-\mathrm{C}_{60}$ and PEDOT:PSS. When the doping content is $2.5 \%$ and the interface barrier is $0.7 \mathrm{eV}$, the highest power factor of $83.2 \mu \mathrm{W}\left(\mathrm{m} \mathrm{K}^{2}\right)^{-1}$ is acquired, which is 19 times better than that of pure PEDOT:PSS. On the other hand, because the F-C 60 nanoparticles on the surface of rGO can effectively scatter phonons and hinder the heat transport, the thermoelectric figure of merit is finally 0.1 , which is the highest thermoelectric figure of merit of graphene-based composite thermoelectric materials that have been reported to date.

Park et al. introduced the PEDOT:PSS conducting polymer via spin coating to cover the defects on the graphene film surface and fabricate a graphene/PEDOT:PSS transparent composite film. As shown in Fig. 12, RTCVD graphene was transferred onto a PET substrate and was irradiated with ultraviolet light. Then, PEDOT:PSS doped with $5 \mathrm{wt} \%$ DMSO was dropped onto the RTCVD graphene film via spin coating. The residual solvents were evaporated via an annealing process at $150{ }^{\circ} \mathrm{C}$ for $2 \mathrm{~min}$. The sheet resistance of the composite film had a $48 \%$ decrease compared with that of the graphene film. Although the Seebeck coefficient decreased slightly, higher $Z T$ could be 


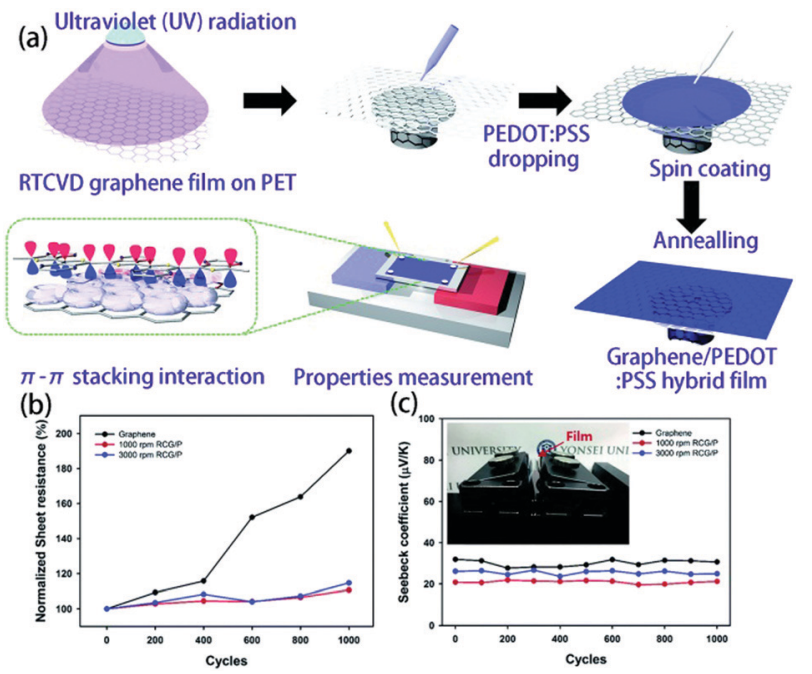

Fig. 12 (a) Schematics of the hybridization process of RTCVD graphene and PEDOT:PSS and the $\pi-\pi$ stacking interaction interface between graphene and the PEDOT:PSS chains. (b) Plots of the sheet resistance and (c) Seebeck coefficient versus the bending cycle number of the graphene film and RCG/P hybrid films. (Reproduced from ref. 149 with permission from AIP.).

obtained with lower thermal conductivity. ${ }^{149}$ More interestingly, the PEDOT:PSS thin film reduced the surface defects and improved the bending stability of the film. Due to the constrained distortion of graphene during the bending stress, the thermoelectric performance remained stable after 1000 cycles.

\section{Other inorganic-based composites}

In addition to chalcogenide composites and carbon-based composites for the preparation of flexible thermoelectric films, other inorganic fillers, such as oxides and nickel-cobalt fibers, are used to fabricate flexible thermoelectric elements.

\subsection{Oxides}

Andrei et al. prepared a thermoelectric paste using a mixture of graphite, cuprous oxide and polychlorotrifluoroethylene. ${ }^{150}$ By adjusting the ratio between graphite and cuprous oxide, the Seebeck coefficient of the paste was varied between 10 and $600 \mu \mathrm{V} \mathrm{K} \mathrm{K}^{-1}$ and the conductivity was between $10^{-4}$ and $10^{2} \mathrm{~S} \mathrm{~m}^{-1}$. The maximum power factor of the composite could reach $7 \times 10^{-5} \mu \mathrm{W}\left(\mathrm{m} \mathrm{K}^{2}\right)^{-1}$.

Geppert et al. ${ }^{151}$ prepared a $\mathrm{Ca}_{3} \mathrm{Co}_{4} \mathrm{O}_{9} / \mathrm{CuO} / \mathrm{Ag}$-based ceramic composite to make a p-type thermoelectric leg. $\mathrm{Cu}-\mathrm{Ni}-\mathrm{Mn}$ alloy was used as an n-type leg in the module. The flexible module (P-type leg with $5 \mathrm{~mol} \% \mathrm{Ag}$ and $\mathrm{Cu}$ addition) showed a maximum output power of $60 \mu \mathrm{W}$.

Xin et al. ${ }^{152}$ prepared flexible polypyrrole (PPy) nanotube/ reduced graphene oxide (rGO) hybrid films via vacuum filtration. The unique network in the PPy nanotube/rGO hybrid films can destroy the aggregation of the nanosheets and supply effective channels to conduct the electrons. The power factor of PPy/rGO hybrid film was more than 130 times larger than that of the pure PPy nanotube film. In contrast with other oxide-based composites, the films showed excellent performance stability after repeated mechanical bending.

\subsection{Metal nanowires}

Chen et al. used a magnetic field to align Co nanowires within a poly(vinylidene fluoride) matrix during the process, which significantly decreased the electrical resistivity in comparison to the nanocomposites with random orientation. The maximum power factor of the Co/PVDF composites can reach $500 \mu \mathrm{W} \mathrm{m}{ }^{-1} \mathrm{~K}^{-2}$ at $45{ }^{\circ} \mathrm{C}$. The flexible and planar thermoelectric module were fabricated via pairing these n-type legs with p-type PEDOT:PSS legs, and the maximum output voltage and power were $26.4 \mathrm{mV}$ and $5.2 \mu \mathrm{W}$, respectively, at $\Delta T=50 \mathrm{~K}^{153}$

\section{Hybrid thermoelectric devices and applications}

With the continuous improvement of the fabrication procedure and performance of flexible thermoelectric materials, research on their practical application in devices has attracted increasing attention. The devices can collect heat from the environment for self-energy supply and effectively reduce practical application costs. Combined with their inherent flexibility, hybrid thermoelectric materials and their devices have great potential applications in wearable devices. ${ }^{64,154-156}$ Additionally, some groups have developed different types of actual devices.

\subsection{Thermoelectric generators (TEGs)}

TEGs based on the Seebeck effect are the most basic and widely applied due to their low power consumption and self-powered, maintenance-free operation. ${ }^{129,157,158}$ Flexible TEGs are especially suitable for obtaining thermal energy from heat source surfaces with complex shapes, and they have many potential applications in wearable devices and the internet of things due to their advantages of easy bending, low cost and light weight; thus, they have received extensive attention from the public. Many groups focus on the optimisation of the device fabrication, structure optimization and possible applications.

Park et al. first prepared PEDOT films on a thin polyethyleneterephthalate (PET) film with solution casting polymerization and formed the foils into roll-type legs, which were easily connected to electrodes. These flexible p-type legs were integrated with rigid n-type $\mathrm{Bi}_{2} \mathrm{Te}_{3}$ legs to assemble a rigid-flexible TEG with 36 couples, as shown in Fig. $13 .{ }^{159}$ Due to this combination of rigid and flexible parts, the generator can move like skeletal fingers. The power output under $\Delta T=8 \mathrm{~K}$ is about $120 \mathrm{nW}$ under a resistance of $3.0 \mathrm{k} \Omega$, and the output voltage was $10.6 \mathrm{mV}$, which was generated constantly and steadily from human body heat.

Takashiri et al. proposed and fabricated flexible thin-film TEGs via electrodeposition and transfer processes at a low manufacturing cost. $\mathrm{N}$-type $\mathrm{Bi}_{2} \mathrm{Te}_{3}$ films and p-type $\mathrm{Sb}_{2} \mathrm{Te}_{3}$ films were chosen as $\mathrm{p}$ and $\mathrm{n}$ legs, respectively. Thin stainless-steel 


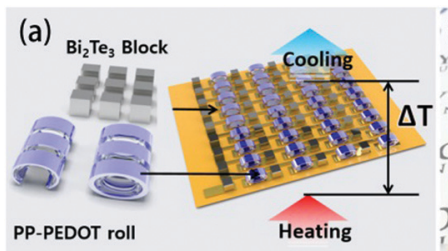

(b)
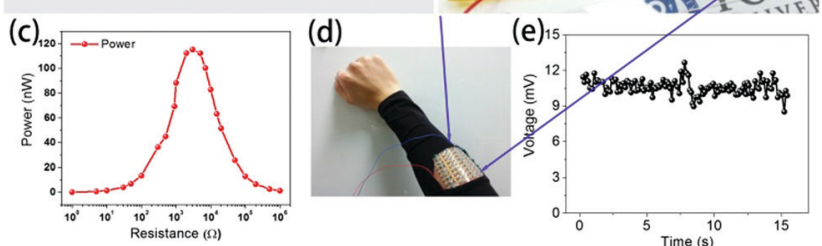

Fig. 13 (a) Schematic of the module structure based on PP-PEDOT rolls and $\mathrm{Bi}_{2} \mathrm{Te}_{3}$ blocks, (b and d) photographic images of an RF-TEG consisting of 36 thermocouples composed of PP-PEDOT rolls and $\mathrm{Bi}_{2} \mathrm{Te}_{3}$ blocks, (c) the maximum power at $\Delta T \sim 8 \mathrm{~K}$ as a function of load resistance, and (e) the output voltage of the module fabricated as a wearable energy harvester. The output voltage of the 36-couple RF-TEG was determined to be $10.6 \mathrm{mV}$, which was generated constantly and steadily from human body heat. (Reproduced from ref. 159 with permission from AIP.).

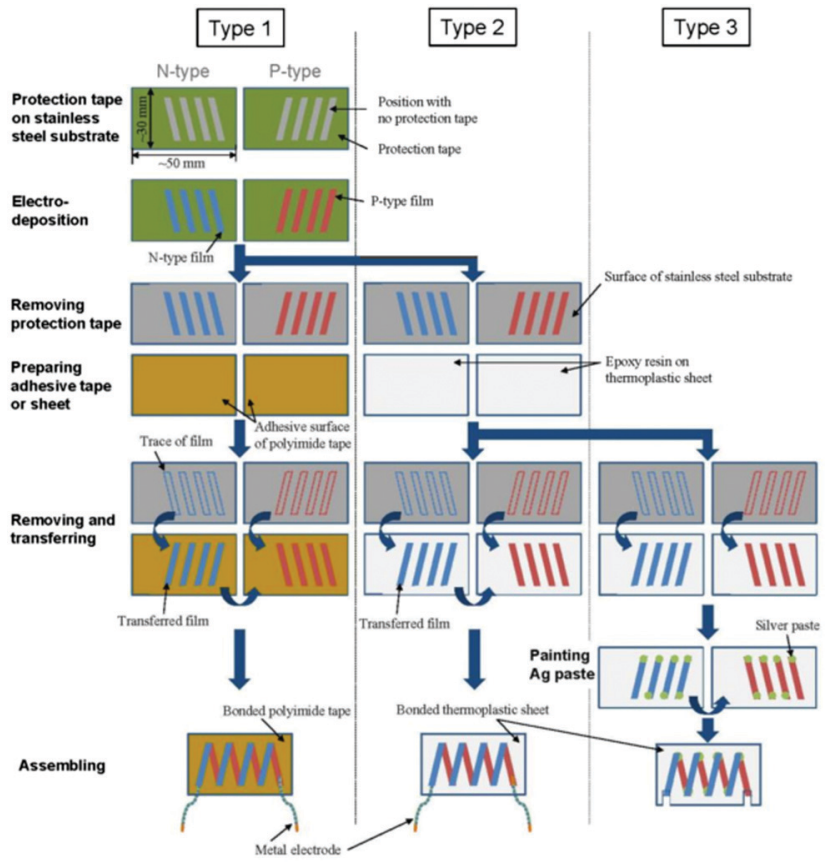

Fig. 14 Schematic process, flow diagram and photographs of the three types of flexible thin-film TEGs. ${ }^{73}$

foil was selected as a substrate material. After electrodeposition was complete, the films were fixed on a glass plate using epoxy resin, subsequently removed from the stainless-steel substrate, and then assembled into different modules, as shown in Fig. 14. The generator had a maximum power of $10.4 \mathrm{nW}$ with a temperature difference of $60 \mathrm{~K}$. The performance of the thinfilm generators can be improved by decreasing the number of micro-cracks and achieving tight connections between different legs using silver paste. ${ }^{73}$
An et al. ${ }^{129}$ chose to directly spin carbon nanotubes with different treatments as $\mathrm{p}$ - and n-type legs and fabricate planar and vertical thermoelectric modules. The free-standing webs of carbon nanotubes were attached to a flexible polyethylene terephthalate (PET) substrate to create an electrical connection, in which each source was electrically connected by Ag paste through a dispensing process. The $20 \mathrm{n}$-type or p-type active legs, with widths of $1.5 \mathrm{~mm}$, lengths of $12 \mathrm{~mm}$, and thicknesses of $20 \mathrm{~mm}$, were cross-connected from the "cold side" of one leg to the "hot side" of the adjacent leg to obtain single-junction TE modules (Fig. 15). The maximum power output of the $\mathrm{p}-\mathrm{n}$ junction TE module increased with increasing temperature gradient, approaching $7.1 \mathrm{~mW}$ at $\Delta T=20 \mathrm{~K}$. A vertical TE module was fabricated by stacking 20 layers of planar $10 \mathrm{p}-\mathrm{n}$ TE couples serially and sandwiching the layers between two ceramic plates to deliver heat homogenously. The voltage and current varied depending on the temperature difference, and a maximum power output of $123 \mathrm{~mW}$ was achieved at $\Delta T=20 \mathrm{~K}$.

Nishino et al. used Ni-based and $\mathrm{Bi}_{2} \mathrm{Te}_{3}$-based thermoelectric materials to develop a flexible TEG. ${ }^{160}$ Thermoelectric materials were first sputter-deposited on a polyimide flexible substrate. Then, the $\mathrm{Bi}_{2} \mathrm{Te}_{3}$-based materials were annealed at $300{ }^{\circ} \mathrm{C}$ to improve their performance, while the Ni-based materials needed no further annealing. A flexible printed film with copper layers was then prepared as the heat path film. The films were integrated with the heat path film via an epoxy adhesive and vacuum lamination to obtain the final TEG, which reached a power density of $0.1 \mu \mathrm{W}\left(\mathrm{K} \mathrm{cm}^{2}\right)^{-1}$. Although the power density was not high, the heat path structure of this device could realize the transition from a longitudinal temperature difference to a lateral temperature difference.

Zhao et al. developed a prototype of a transparent paperbased TEG and supplemented it with a resin impregnation method. ${ }^{161} \mathrm{~N}$-Type and P-type pastes, which contained BiSbTe alloy powders, glycerin, ethylene glycol, and polyvinylpyrrolidone, (a)

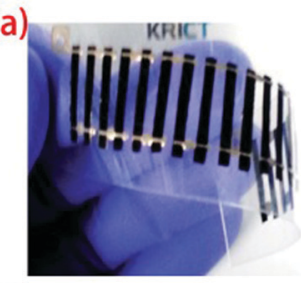

(c)

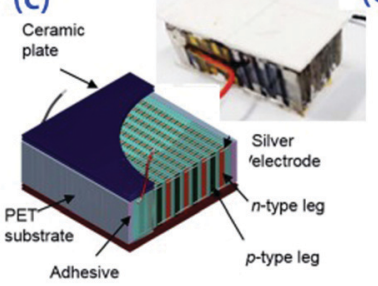

(b)

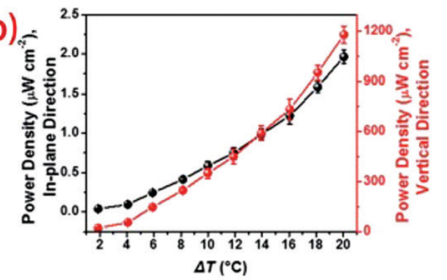

(d)

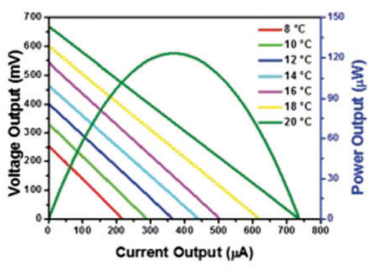

Fig. 15 Fabrication of planar (a) and vertical (c) thermoelectric modules and power densities as a function of temperature gradient for the (b) planar and (d) vertical modules. (Reproduced from ref. 129 with permission from The Royal Society of Chemistry.). 
were alternately dropped onto the PTFE flexible substrate and then covered with another paper substrate. The pastes penetrated into the paper substrate with very slight pressure and were connected by conductive silver pastes. Finally, epoxy resin was placed inside to obtain a prototype of a transparent paper-based TEG. After 1000 bending cycles, this transparent paper-based TEG could maintain a voltage of about $8.3 \mathrm{mV}$ and an output power of about $10 \mathrm{nW}$ at $\Delta T=35 \mathrm{~K}$. Huu et al. proposed a lateral Y-type architecture instead of the traditional vertical $\pi$-type architecture. The electrochemical deposition process was used to fabricate a durable flexible TEG, ${ }^{72}$ and an output power density of $3 \mu \mathrm{W} \mathrm{cm}{ }^{-2}$ was obtained at $\Delta T=22 \mathrm{~K}$.

\subsection{Environmental sensor}

Sensors can continuously monitor various environmental or industrial elements and play key roles in modern industry and life. In recent years, with the development of many polymer-based thermoelectric composites, flexible thermoelectric devices can not only be self-energized by thermal energy in the environment but can also monitor changes in the environment, such as human body temperature and pressure. ${ }^{162-167}$

Seo et al. ${ }^{165}$ developed a dual output sensor based on the structural design of thermoelectric materials (SDTM) which was designed to monitor fluid temperature and dynamics. When the temperature of the working fluid is $312 \mathrm{~K}(\Delta T=14 \mathrm{~K})$, the power density is $42 \mu \mathrm{W} \mathrm{cm}{ }^{-2}$. This power can enable the sensor to analyze real-time signals and transmit the data to an external platform.

Based on the thermoelectric effects of graphene, Hou et al. ${ }^{166}$ demonstrated a simple flexible human touch sensor. The sensor is self-powered from its own thermoelectric conversion effect and can sense heating or cooling of the local area and pressure to perceive a person's touch position, which suggests unique potential application value in the development of electronic skin.

\subsection{Refrigeration applications}

Hou et $a .^{52}$ developed a very simple method for preparing a flexible TE cooling device. $\mathrm{Bi}_{0.5} \mathrm{Sb}_{1.5} \mathrm{Te}_{3}$ was the thermoelectric component and epoxy resin was the binder; they were brushed on a polyimide flexible substrate and then hot-pressed in a curing process. An $\mathrm{Al} / \mathrm{Cu} / \mathrm{Ni}$ multilayer film electrode was deposited on the polyimide substrate by vacuum evaporation. The prototype of the refrigeration unit was $60 \mathrm{~mm}$ long and $260 \mu \mathrm{m}$ thick. The hot and cold ends of the device prototype could establish a stable temperature difference of $6.2 \mathrm{~K}$ at a current of $0.06 \mathrm{~A}$. Meanwhile, when the bending radius was between $20 \mathrm{~mm}$ and $90 \mathrm{~mm}$, the resistance of the device remained almost unchanged after 2500 bending recovery cycles. Additionally, $\mathrm{Lu}$ et al. $^{57}$ and Wu et al. ${ }^{168}$ fabricated a film refrigeration device through inkjet printing technology and a simple brushing technique, respectively. Both could achieve a stable temperature difference of about $3.2 \mathrm{~K}$.

\section{Conclusions and outlook}

The key advantages of organic/inorganic thermoelectric composites are their flexibility and easy fabrication. Due to both points, these composites are uniquely competitive in the application of collecting energy from waste heat or the environment to supply electricity to wireless communication units, physical sensors and wearable electronics, which create low-grade waste heat. However, this technology is still in a primitive stage and will face many challenges in the future. These include:

(1) Telluride is a key inorganic material used in thermoelectric composites which has excellent $Z T$ values (about 1 or higher). However, Te is a rare earth element which only accounts for $0.005 \mathrm{ppm}$ of the crustal content. Meanwhile, this element is also toxic and harmful to the nerves, liver, gastrointestinal tract and reproductive system of human beings. If Te is used in MEMS circuits or sensors, it is difficult to recycle it; therefore, the application and development of thermoelectric modules is unsustainable and pollutes the environment. Thus, it is urgent to seek new inorganic fillers with excellent performance and low cost.

(2) Due to the non-uniform particle size distributions, agglomeration and interfacial problems of inorganic materials, their thermoelectric performance is very sensitive to the fabrication process, which weakens the actual composite mechanism. Therefore, it may be meaningless to improve the properties of the matrix and fillers. In order to correctly picture the possible physical mechanisms, it is necessary to develop better chemical processes to obtain original powders and inks with high quality.

(3) As stated in Section 2, "Scientific mechanisms in organic/ inorganic thermoelectric composites", percolation theory, grain boundaries and interface effects, and superlattice effects/energy filter effects are used to enhance the performance of organic/ inorganic thermoelectric composites. However, markedly different results have been obtained for similar composites by different scientific groups worldwide. After removing the measurement error, these differences arise from the intrinsic properties of the matrix and fillers, which are somewhat sensitive to the synthesis parameters. Meanwhile, dirt on the interfaces between these phases and the environment also deteriorates the transport properties of composite materials. Scientists should not focus only on physical properties while ignoring these technical details.

(4) Due to very weak electric signals during the measurement, the Seebeck coefficient values are somewhat unreliable and inaccurate. As a result, the reported thermoelectric properties and power densities of the devices are different, with values ranging from several $\mu \mathrm{W}\left(\mathrm{m} \mathrm{K}^{2}\right)^{-1}$ to a thousand $\mu \mathrm{W}\left(\mathrm{m} \mathrm{K}^{2}\right)^{-1}$. Meanwhile, the thermal diffusivity model to evaluate the thermal conductivity of films and fibers is very poor, unlike that of their thermoelectric bulks. Combined with the anisotropy of $2 \mathrm{D}$ or layered structured films, the $Z T$ values of these films must therefore be double-checked in future.

(5) With the rapid development of integrated circuits, lower energy consumption is needed for devices. In view of their foreseeable commercial applications, it is more urgent to develop large-scale fabrication techniques to produce films of high quality and high efficiency (such as ink printing and screen printing) than to improve the performance of the materials. 


\section{Conflicts of interest}

There are no conflicts to declare.

\section{Acknowledgements}

This work was supported by the National Natural Science Foundation of China (NSFC No. 51772019, 51572098, 51632006), National Key Research and Development Plan of China (2018YFB1503100), and NSFC-Royal Society joint project (5171101927).

\section{Notes and references}

1 D. S. Ayou and V. Eveloy, Energy Convers. Manage., 2020, 213, 112790.

2 A. P. Straub, N. Y. Yip, S. H. Lin, J. Lee and M. Elimelech, Nat. Energy, 2016, 1, 16090, DOI: 10.1038/nenergy.2016.90.

3 Y. Ammar, S. Joyce, R. Norman, Y. D. Wang and A. P. Roskilly, Appl. Energy, 2012, 89, 3-20.

4 I. Chowdhury, R. Prasher, K. Lofgreen, G. Chrysler, S. Narasimhan, R. Mahajan, D. Koester, R. Alley and R. Venkatasubramanian, Nat. Nanotechnol., 2009, 4, 235-238.

5 J. Xin, Y. Tang, Y. Liu, X. Zhao, H. Pan and T. Zhu, npj Quant. Mater., 2018, 3, 9.

6 M. Jin, Z. Chen, X. Tan, H. Shao, G. Liu, H. Hu, J. Xu, B. Yu, H. Shen, J. Xu, H. Jiang, Y. Pei and J. Jiang, ACS Energy Lett., 2018, 3, 689-694.

7 Q. Jiang, H. Hu, J. Yang, J. Xin, S. Li, G. Viola and H. Yan, ACS Appl. Mater. Interfaces, 2020, 12, 23102-23109.

8 S. Duan, N. Man, J. Xu, Q. Wu, G.-q. Liu, X. Tan, H. Shao, K. Guo, X. Yang and J. Jiang, J. Mater. Chem. A, 2019, 7, 9241-9246.

9 L. Mao, Y. Yin, Q. Zhang, G.-Q. Liu, H. Wang, Z. Guo, H. Hu, Y. Xiao, X. Tan and J. Jiang, Energy Environ. Sci., 2020, 13, 616-621.

10 S. Li, J. Yang, Y. Liu, J. Xin, S. Li, Q. Long and Q. Jiang, Adv. Appl. Ceram., 2020, 119, 107-113.

11 G. M. Chen, W. Xu and D. B. Zhu, J. Mater. Chem. C, 2017, 5, 4350-4360.

12 C. W. Nan, Y. Shen and J. Ma, in Annual Review Of Materials Research, ed. D. R. Clarke, M. Ruhle and F. Zok, 2010, vol. 40, pp. 131-151.

13 N. Rolland, J. F. Franco-Gonzalez, R. Volpi, M. Linares and I. V. Zozoulenko, Phys. Rev. Mater., 2018, 2, 045605.

14 J. Liu, L. Qiu, R. Alessandri, X. Qiu, G. Portale, J. Dong, W. Talsma, G. Ye, A. A. Sengrian, P. C. T. Souza, M. A. Loi, R. C. Chiechi, S. J. Marrink, J. C. Hummelen and L. J. A. Koster, Adv. Mater., 2018, 30, 1704630.

15 I. Petsagkourakis, E. Pavlopoulou, E. Cloutet, Y. F. Chen, X. Liu, M. Fahlman, M. Berggren, X. Crispin, S. Dilhaire, G. Fleury and G. Hadziioannou, Org. Electron., 2018, 52, 335-341.

16 Q. Jiang, H. Yan, J. Khaliq, Y. Shen, K. Simpson and M. J. Reece, J. Mater. Chem. A, 2014, 2, 9486-9489.
17 A. Gharleghi, Y. Liu, M. Zhou, J. He, T. M. Tritt and C.-J. Liu, J. Mater. Chem. A, 2016, 4, 13874-13880.

18 L. Horta Romarís, M. V. González Rodríguez, B. Huang, P. Costa, A. Lasagabáster Latorre, S. Lanceros-Mendez and M. J. Abad López, J. Mater. Chem. C, 2018, 6, 8502-8512.

19 B. Liu, L. Dong, Q. Xi, X. F. Xu, J. Zhou and B. W. Li, Front. Energy, 2018, 12, 72-86.

20 B. Shi, L. Dong, M. Li, B. Liu, K. Kim, X. Xu, J. Zhou and J. Liu, Appl. Phys. Lett., 2018, 113, 041902.

21 T. Zhu, Y. Liu, C. Fu, J. P. Heremans, J. G. Snyder and X. Zhao, Adv. Mater., 2017, 29, 1605884.

22 L.-D. Chen, Z. Xiong and S.-Q. Bai, J. Inorg. Mater., 2010, 25, 561-568.

23 T.-R. Wei, Y. Qin, T. Deng, Q. Song, B. Jiang, R. Liu, P. Qiu, X. Shi and L. Chen, Sci. China Mater., 2019, 62, 8-24.

24 K. Biswas, J. He, I. D. Blum, C.-I. Wu, T. P. Hogan, D. N. Seidman, V. P. Dravid and M. G. Kanatzidis, Nature, 2012, 489, 414.

25 V. Andrei, K. Bethke, F. Madzharova, S. Beeg, A. KnopGericke, J. Kneipp and K. Rademann, Adv. Electron. Mater., 2017, 3, 1600473.

26 D. Ni, Y. Chen, H. Song, C. Liu, X. Yang and K. Cai, J. Mater. Chem. A, 2019, 7, 1323-1333.

27 Y. Du, K. F. Cai, S. Chen, P. Cizek and T. Lin, ACS Appl. Mater. Interfaces, 2014, 6, 5735-5743.

28 L. D. Hicks and M. S. Dresselhaus, Phys. Rev. B: Condens. Matter Mater. Phys., 1993, 47, 12727-12731.

29 R. Venkatasubramanian, E. Siivola, T. Colpitts and B. O'Quinn, Nature, 2001, 413, 597-602.

30 A. Giri, J. P. Niemela, C. J. Szwejkowski, M. Karppinen and P. E. Hopkins, Phys. Rev. B, 2016, 93, 024201.

31 M. G. Kanatzidis, R. Bissessur, D. C. DeGroot, J. L. Schindler and C. R. Kannewurf, Chem. Mater., 1993, 5, 595-596.

32 C. Wan, X. Gu, F. Dang, T. Itoh, Y. Wang, H. Sasaki, M. Kondo, K. Koga, K. Yabuki, G. J. Snyder, R. Yang and K. Koumoto, Nat. Mater., 2015, 14, 622-627.

33 C. Wan, R. Tian, M. Kondou, R. Yang, P. Zong and K. Koumoto, Nat. Commun., 2017, 8, 1024.

34 D. Jariwala, T. J. Marks and M. C. Hersam, Nat. Mater., 2017, 16, 170-181.

35 K. S. Novoselov, A. Mishchenko, A. Carvalho and A. H. Castro Neto, Science, 2016, 353, aac9439.

36 C. Wang, Q. He, U. Halim, Y. Liu, E. Zhu, Z. Lin, H. Xiao, X. Duan, Z. Feng, R. Cheng, N. Weiss, G. Ye, Y.-C. Huang, H. Wu, H.-C. Cheng, I. Shakir, L. Liao, X. Chen, W. A. Goddard, Y. Huang and X. Duan, Nature, 2018, 555, 231-236.

37 X. Wang, M. Zebarjadi and K. Esfarjani, Nanoscale, 2016, 8, 14695-14704.

38 Y. Lu, Y. Qiu, K. Cai, Y. Ding, M. Wang, C. Jiang, Q. Yao, C. Huang, L. Chen and J. He, Energy Environ. Sci., 2020, 13, 1240-1249.

39 S. Cavaliere, S. Subianto, I. Savych, D. J. Jones and J. Roziere, Energy Environ. Sci., 2011, 4, 4761-4785.

40 B. Ding, M. R. Wang, X. F. Wang, J. Y. Yu and G. Sun, Mater. Today, 2010, 13, 16-27. 
41 N. Dalton, R. P. Lynch, M. N. Collins and M. Culebras, Int. J. Biol. Macromol., 2019, 121, 472-479.

42 Y. A. Shah, M. J. Iqbal, K. Rasool, A. U. R. Makhdoom, Y. Iqbal, A. Ullah and M. Habib, Appl. Phys. A: Mater. Sci. Process., 2020, 126, 376.

43 A. C. Marques, D. Miglietta, G. Gaspar, A. C. Baptista, A. Gaspar, P. Perdigao, I. Soares, C. Bianchi, D. Sousa, B. M. M. Faustino, V. S. Amaral, T. Santos, A. P. Goncalves, R. C. da Silva, F. Giorgis and I. Ferreira, Mater. Renewable Sustainable Energy, 2019, 8, 21.

44 M. Zhang, S.-D. Park, J. Kim, M. Nalbandian, S. Kim, Y. Choa, J. Lim and N. V. Myung, Front. Chem., 2018, 6, 436.

45 Q. Wang, Q. Yao, J. Chang and L. D. Chen, J. Mater. Chem., 2012, 22, 17612-17618.

46 J. A. Lee, A. E. Aliev, J. S. Bykova, M. J. de Andrade, D. Kim, H. J. Sim, X. Lepro, A. A. Zakhidov, J. B. Lee, G. M. Spinks, S. Roth, S. J. Kim and R. H. Baughman, Adv. Mater., 2016, 28, 5038-5044.

47 Q. Jiang, H. Yan, Y. Lin, Y. Shen, J. Yang and M. J. Reece, J. Mater. Chem. A, 2020, 8, 10909-10916.

48 M. S. Dresselhaus, G. Chen, M. Y. Tang, R. Yang, H. Lee, D. Wang, Z. Ren, J.-P. Fleurial and P. Gogna, Adv. Mater., 2007, 19, 1043-1053.

49 H. Wang, C. Xiong, G. Luo, H. Hu, B. Yu, H. Shao, X. Tan, J. Xu, G. Liu, J. G. Noudem and J. Jiang, Energy Technol., 2019, 7, 1900814.

50 C. Tan, X. Tan, B. Yu, G.-Q. Liu, H. Wang, G. Luo, J. Xu, Q. Wu, B. Liang and J. Jiang, ACS Appl. Energy Mater., 2019, 2, 6714-6719.

51 J. Kim, O. H. Kwon, Y. H. Kang, K. S. Jang, S. Y. Cho and Y. Yoo, Compos. Sci. Technol., 2017, 153, 32-39.

52 W. Hou, X. Nie, W. Zhao, H. Zhou, X. Mu, W. Zhu and Q. Zhang, Nano Energy, 2018, 50, 766-776.

53 Q. Jiang, F. Liu, H. Yan, H. Ning, Z. Libor, Q. Zhang, M. Cain and M. J. Reece, J. Am. Ceram. Soc., 2011, 94, 2311-2314.

54 Q. Jiang, H. Ning, Q. Zhang, M. Cain, M. J. Reece and H. Yan, J. Mater. Chem. C, 2013, 1, 5628-5631.

55 Q. Jiang, J. Yang, J. Xin, Z. Zhou, D. Zhang and H. Yan, J. Alloys Compd., 2017, 694, 864-868.

56 Z.-H. Ge, Y. Chang, F. Li, J. Luo and P. Fan, Chem. Commun., 2018, 54, 2429-2431.

57 K. Wei and G. S. Nolas, Scr. Mater., 2018, 150, 70-73.

58 D. B. Kuang, A. W. Xu, Y. P. Fang, H. Q. Liu, C. Frommen and D. Fenske, Adv. Mater., 2003, 15, 1747-1750.

59 M. He, J. Ge, Z. Lin, X. Feng, X. Wang, H. Lu, Y. Yang and F. Qiu, Energy Environ. Sci., 2012, 5, 8351-8358.

60 J. Gao, C. Liu, L. Miao, X. Wang, Y. Peng and Y. Chen, RSC Adv., 2016, 6, 31580-31587.

61 Z. Lin, C. Hollar, J. S. Kang, A. Yin, Y. Wang, H.-Y. Shiu, Y. Huang, Y. Hu, Y. Zhang and X. Duan, Adv. Mater., 2017, 29.

62 H. Choi, Y. J. Kim, C. S. Kim, H. M. Yang, M.-W. Oh and B. J. Cho, Nano Energy, 2018, 46, 39-44.

63 T. Varghese, C. Hollar, J. Richardson, N. Kempf, C. Han, P. Gamarachchi, D. Estrada, R. J. Mehta and Y. Zhang, Sci. Rep., 2016, 6, 33135.
64 S. J. Kim, J. H. We and B. J. Cho, Energy Environ. Sci., 2014, 7, 1959-1965.

65 Z. Yuan, X. Tang, Z. Xu, J. Li, W. Chen, K. Liu, Y. Liu and Z. Zhang, Appl. Energy, 2018, 225, 746-754.

66 H. Choi, S. J. Kim, Y. Kim, J. H. We, M.-W. Oh and B. J. Cho, J. Mater. Chem. C, 2017, 5, 8559-8565.

67 C. Han, G. Tan, T. Varghese, M. G. Kanatzidis and Y. Zhang, ACS Energy Lett., 2018, 3, 818-822.

68 Y. Wang, S. M. Zhang and Y. Deng, J. Mater. Chem. A, 2016, 4, 3554-3559.

69 H. S. Cho, H. X. Deng, K. Miyasaka, Z. Y. Dong, M. Cho, A. V. Neimark, J. K. Kang, O. M. Yaghi and O. Terasaki, Nature, 2015, 527, 503-507.

70 J. P. Niemela, A. J. Karttunen and M. Karppinen, J. Mater. Chem. C, 2015, 3, 10349-10361.

71 N. H. Trung, N. Van Toan and T. Ono, J. Micromech. Microeng., 2017, 27, 125006.

72 T. Nguyen Huu, T. Nguyen Van and O. Takahito, Appl. Energy, 2018, 210, 467-476.

73 H. Yamamuro, N. Hatsuta, M. Wachi, Y. Takei and M. Takashiri, Coatings, 2018, 8.

74 M. Culebras, A. M. Igual-Muñoz, C. Rodríguez-Fernández, M. I. Gómez-Gómez, C. Gómez and A. Cantarero, ACS Appl. Mater. Interfaces, 2017, 9, 20826-20832.

75 S. M. George, Chem. Rev., 2010, 110, 111-131.

76 S. M. George, B. Yoon and A. A. Dameron, Acc. Chem. Res., 2009, 42, 498-508.

77 S. P. Lonkar, V. V. Pillai and S. M. Alhassan, Sci. Rep., 2018, 8, 13401.

78 J. Cho, J. Park and J. An, J. Eur. Ceram. Soc., 2017, 37, 3131-3136.

79 T. Sarnet, T. Hatanpää, M. Vehkamäki, T. Flyktman, J. Ahopelto, K. Mizohata, M. Ritala and M. Leskelä, J. Mater. Chem. C, 2015, 3, 4820-4828.

80 T. Tynell, A. Giri, J. Gaskins, P. E. Hopkins, P. Mele, K. Miyazaki and M. Karppinen, J. Mater. Chem. A, 2014, 2, 12150-12152.

81 H. S. Mann, B. N. Lang, Y. Schwab, J.-P. Niemelä, M. Karppinen and G. Scarel, J. Vac. Sci. Technol., A, 2014, 33, 01A124.

82 L. Zheng, X. Cheng, D. Cao, Q. Wang, Z. Wang, C. Xia, L. Shen, Y. Yu and D. Shen, RSC Adv., 2015, 5, 40007-40011.

83 S. Lee, J.-H. Han, S.-H. Lee, G.-H. Baek and J.-S. Park, JOM, 2019, 71, 197-211.

84 K. L. Jarvis and P. J. Evans, Thin Solid Films, 2017, 624, 111-135.

85 J. Sheng, K.-L. Han, T. Hong, W.-H. Choi and J.-S. Park, J. Semicond., 2018, 39, 011008.

86 G. K. Hyde, K. J. Park, S. M. Stewart, J. P. Hinestroza and G. N. Parsons, Langmuir, 2007, 23, 9844-9849.

87 J. P. Niemelä, A. J. Karttunen and M. Karppinen, J. Mater. Chem. C, 2015, 3, 10349-10361.

88 A. J. Karttunen, L. Sarnes, R. Townsend, J. Mikkonen and M. Karppinen, Adv. Electron. Mater., 2017, 3, 1600459.

89 L. L. Shen, P. P. Liu, C. C. Liu, Q. L. Jiang, J. K. Xu, X. M. Duan, Y. K. Du and F. X. Jiang, ACS Appl. Polym. Mater., 2020, 2, 376-384. 
90 G. D. Cummins and M. P. Yves, Circuit World, 2012, 38, 193-213.

91 M. Orrill and S. LeBlanc, J. Appl. Polym. Sci., 2017, 134, 44256.

92 Z. Yin, Y. Huang, N. Bu, X. Wang and Y. Xiong, Chin. Sci. Bull., 2010, 55, 3383-3407.

93 E. Tekin, P. J. Smith and U. S. Schubert, Soft Matter, 2008, 4, 703-713.

94 D. Kim, S. Jeong, B. K. Park and J. Moon, Appl. Phys. Lett., 2006, 89, 264101.

95 M. Kuang, L. Wang and Y. Song, Adv. Mater., 2014, 26, 6950-6958.

96 K. T. Park, J. Choi, B. Lee, Y. Ko, K. Jo, Y. M. Lee, J. A. Lim, C. R. Park and H. Kim, J. Mater. Chem. A, 2018, 6, 19727-19734.

97 T. Juntunen, H. Jussila, M. Ruoho, S. Liu, G. Hu, T. AlbrowOwen, L. W. T. Ng, R. C. T. Howe, T. Hasan, Z. Sun and I. Tittonen, Adv. Funct. Mater., 2018, 28, 1800480.

98 S. Horike, T. Fukushima, T. Saito, T. Kuchimura, Y. Koshiba, M. Morimoto and K. Ishida, Mol. Syst. Des. Eng., 2017, 2, 616-623.

99 B. Chen, S. R. Das, W. Zheng, B. Zhu, B. Xu, S. Hong, C. Sun, X. Wang, Y. Wu and J. C. Claussen, Adv. Electron. Mater., 2017, 3, 1600524.

100 Z. Lu, M. Layani, X. Zhao, L. P. Tan, T. Sun, S. Fan, Q. Yan, S. Magdassi and H. H. Hng, Small, 2014, 10, 3551-3554.

101 S. Ferhat, C. Domain, J. Vidal, D. Noël, B. Ratier and B. Lucas, Sustainable Energy Fuels, 2018, 2, 199-208.

102 K. Kato, H. Hagino and K. Miyazaki, J. Electron. Mater., 2013, 42, 1313-1318.

103 B. Chen, M. Kruse, B. Xu, R. Tutika, W. Zheng, M. D. Bartlett, Y. Wu and J. C. Claussen, Nanoscale, 2019, 11, 5222-5230.

104 M. He, Y. Zhao, B. Wang, Q. Xi, J. Zhou and Z. Liang, Small, 2015, 11, 5889-5894.

105 F. Kim, B. Kwon, Y. Eom, J. E. Lee, S. Park, S. Jo, S. H. Park, B.-S. Kim, H. J. Im, M. H. Lee, T. S. Min, K. T. Kim, H. G. Chae, W. P. King and J. S. Son, Nat. Energy, 2018, 3, 301-309.

106 J. Wang, H. Li, R. Liu, L. Li, Y.-H. Lin and C.-W. Nan, Compos. Sci. Technol., 2018, 157, 1-9.

107 U. Kalsoom, P. N. Nesterenko and B. Paull, RSC Adv., 2016, 6, 60355-60371.

108 S. Qu, Q. Yao, L. Wang, Z. Chen, K. Xu, H. Zeng, W. Shi, T. Zhang, C. Uher and L. Chen, NPG Asia Mater., 2016, 8, e292.

109 L. Wang, Z. Zhang, Y. Liu, B. Wang, L. Fang, J. Qiu, K. Zhang and S. Wang, Nat. Commun., 2018, 9, 3817.

110 B. Zhang, J. Sun, H. E. Katz, F. Fang and R. L. Opila, ACS Appl. Mater. Interfaces, 2010, 2, 3170-3178.

111 C. Ou, A. L. Sangle, A. Datta, Q. Jing, T. Busolo, T. Chalklen, V. Narayan and S. Kar-Narayan, ACS Appl. Mater. Interfaces, 2018, 10, 19580-19587.

112 H. Song, C. Liu, H. Zhu, F. Kong, B. Lu, J. Xu, J. Wang and F. Zhao, J. Electron. Mater., 2013, 42, 1268-1274.

113 C. Z. Meng, C. H. Liu and S. S. Fan, Adv. Mater., 2010, 22, 535-539.
114 S. Qu, M. Wang, Y. Chen, Q. Yao and L. Chen, RSC Adv., 2018, 8, 33855-33863.

115 Q. Yao, Q. Wang, L. Wang and L. Chen, Energy Environ. Sci., 2014, 7, 3801-3807.

116 C. Yu, K. Choi, L. Yin and J. C. Grunlan, ACS Nano, 2011, 5, 7885-7892.

117 K. Zhang, S. R. Wang, X. Zhang, Y. Zhang, Y. Cui and J. J. Qiu, Nano Energy, 2015, 13, 327-335.

118 J. Xiang and L. T. Drzal, Polymer, 2012, 53, 4202-4210.

119 K. Zhang, Y. Zhang and S. Wang, Sci. Rep., 2013, 3, 3448.

120 Y. Sun, H. Cheng, S. Gao, Q. Liu, Z. Sun, C. Xiao, C. Wu, S. Wei and Y. Xie, J. Am. Chem. Soc., 2012, 134, 20294-20297.

121 Q. Jiang, H. Yan, J. Khaliq, H. Ning, S. Grasso, K. Simpson and M. J. Reece, J. Mater. Chem. A, 2014, 2, 5785-5790.

122 L. Hu, T. Zhu, X. Liu and X. Zhao, Adv. Funct. Mater., 2014, 24, 5211-5218.

123 J. H. We, S. J. Kim and B. J. Cho, Energy, 2014, 73, 506-512.

124 C. Dun, C. A. Hewitt, H. Huang, J. Xu, C. Zhou, W. Huang, Y. Cui, W. Zhou, Q. Jiang and D. L. Carroll, Nano Energy, 2015, 18, 306-314.

125 H. Ju and J. Kim, ACS Nano, 2016, 10, 5730-5739.

126 C. Bounioux, P. Díaz-Chao, M. Campoy-Quiles, M. S. Martín-González, A. R. Goñi, R. Yerushalmi-Rozen and C. Müller, Energy Environ. Sci., 2013, 6, 918-925.

127 W. Lee, C. T. Hong, O. H. Kwon, Y. Yoo, Y. H. Kang, J. Y. Lee, S. Y. Cho and K.-S. Jang, ACS Appl. Mater. Interfaces, 2015, 7, 6550-6556.

128 P. H. Jiang, H. J. Liu, D. D. Fan, L. Cheng, J. Wei, J. Zhang, J. H. Liang and J. Shi, Phys. Chem. Chem. Phys., 2015, 17, 27558-27564.

129 C. J. An, Y. H. Kang, H. Song, Y. Jeong and S. Y. Cho, J. Mater. Chem. A, 2017, 5, 15631-15639.

130 S. Mohammad Mahdi Dadfar, G. Kavoosi and S. Mohammad Ali Dadfar, Polym. Compos., 2014, 35, 1736-1743.

131 C. A. Hewitt, A. B. Kaiser, S. Roth, M. Craps, R. Czerw and D. L. Carroll, Nano Lett., 2012, 12, 1307-1310.

132 B. Massoumi, P. Jafarpour, M. Jaymand and A. A. Entezami, Polym. Int., 2015, 64, 689-695.

133 W. Lee, Y. H. Kang, J. Y. Lee, K.-S. Jang and S. Y. Cho, RSC Adv., 2016, 6, 53339-53344.

134 M. L. Wu, Y. Chen, L. Zhang, H. Zhan, L. Qiang and J. N. Wang, ACS Appl. Mater. Interfaces, 2016, 8, 8137-8144.

135 J.-Y. Kim, J.-H. Mo, Y. H. Kang, S. Y. Cho and K.-S. Jang, Nanoscale, 2018, 10, 19766-19773.

136 Y. Zhou, X. J. Yin, Y. J. Liu, X. Y. Zhou, T. Wan, S. C. Wang, C. M. Gao and L. Wang, ACS Sustainable Chem. Eng., 2019, 7, 11832-11840.

137 M. Golub and A. Graja, J. Phys. D: Appl. Phys., 2003, 36, 3064-3068.

138 T. Kawamoto, M. Ashizawa, T. Mori, J. Yamaura, R. Kato, Y. Misaki and K. Tanaka, Bull. Chem. Soc. Jpn., 2002, 75, 435-447.

139 D. Z. Huang, C. Wang, Y. Zou, X. X. Shen, Y. P. Zang, H. G. Shen, X. K. Gao, Y. P. Yi, W. Xu, C. A. Di and D. B. Zhu, Angew. Chem., Int. Ed., 2016, 55, 10672-10675. 
140 D. Z. Huang, H. Y. Yao, Y. T. Cui, Y. Zou, F. J. Zhang, C. Wang, H. G. Shen, W. L. Jin, J. Zhu, Y. Diao, W. Xu, C. A. Di and D. B. Zhu, J. Am. Chem. Soc., 2017, 139, 13013-13023.

141 Y. Kiyota, T. Kawamoto, H. Mori and T. Mori, J. Mater. Chem. A, 2018, 6, 2004-2010.

142 C. Y. Gao and G. M. Chen, Small, 2018, 14.

143 Y. L. Chen, S. Y. Qu, W. Shi, Q. Yao and L. D. Chen, Carbon, 2020, 159, 471-477.

144 X. J. Yin, Y. H. Peng, J. J. Luo, X. Y. Zhou, C. M. Gao, L. Wang and C. L. Yang, J. Mater. Chem. A, 2018, 6, 8323-8330.

145 J. Tan, Z. Chen, D. Wang, S. Qin, X. Xiao, D. Xie, D. Liu and L. Wang, J. Mater. Chem. A, 2019, 7, 24982-24991.

146 H. X. Kong, Curr. Opin. Solid State Mater. Sci., 2013, 17, 31-37.

147 S. Nardecchia, D. Carriazo, M. L. Ferrer, M. C. Gutiérrez and F. del Monte, Chem. Soc. Rev., 2013, 42, 794-830.

148 S.-H. Hwang, H. W. Park and Y.-B. Park, Smart Mater. Struct., 2013, 22, 015013.

149 C. Park, D. Yoo, S. Im, S. Kim, W. Cho, J. Ryu and J. H. Kim, RSC Adv., 2017, 7, 25237-25243.

150 V. Andrei, K. Bethke and K. Rademann, Phys. Chem. Chem. Phys., 2016, 18, 10700-10707.

151 B. Geppert, A. Brittner, L. Helmich, M. Bittner and A. Feldhoff, J. Electron. Mater., 2017, 46, 2356-2365.

152 S. Xin, N. Yang, F. Gao, J. Zhao, L. Li and C. Teng, Mater. Chem. Phys., 2018, 212, 440-445.

153 Y. Chen, M. He, J. Tang, G. C. Bazan and Z. Liang, Adv. Electron. Mater., 2018, 4, 1800200.

154 J. Y. Oh, J. H. Lee, S. W. Han, S. S. Chae, E. J. Bae, Y. H. Kang, W. J. Choi, S. Y. Cho, J.-O. Lee, H. K. Baik and T. Il Lee, Energy Environ. Sci., 2016, 9, 1696-1705.
155 F. Suarez, A. Nozariasbmarz, D. Vashaee and M. C. Ozturk, Energy Environ. Sci., 2016, 9, 2099-2113.

156 P. Yang, K. Liu, Q. Chen, X. Mo, Y. Zhou, S. Li, G. Feng and J. Zhou, Angew. Chem., Int. Ed., 2016, 55, 12050-12053.

157 J. Choi, K. Cho and S. Kim, Adv. Energy Mater., 2017, 7, 1602138.

158 K. Liu, T. Ding, J. Li, Q. Chen, G. Xue, P. Yang, M. Xu, Z. L. Wang and J. Zhou, Adv. Energy Mater., 2018, 8, 1702481.

159 T. Park, H. Lim, J. U. Hwang, J. Na, H. Lee and E. Kim, APL Mater., 2017, 5, 074106.

160 T. Nishino and T. Suzuki, J. Micromech. Microeng., 2017, 27, 035011.

161 X. Zhao, W. Han, C. Zhao, S. Wang, F. Kong, X. Ji, Z. Li and X. Shen, ACS Appl. Mater. Interfaces, 2019, 11, 10301-10309.

162 W. Zhu, Y. Deng and L. Cao, Nano Energy, 2017, 34, 463-471.

163 E. M. F. Vieira, J. Figueira, A. L. Pires, J. Grilo, M. F. Silva, A. M. Pereira and L. M. Goncalves, J. Alloys Compd., 2019, 774, 1102-1116.

164 P. Zhu, Y. Wang, M. Sheng, Y. Wang, Y. Yu and Y. Deng, J. Mater. Chem. A, 2019, 7, 8258-8267.

165 B. Seo, H. Hwang, S. Kang, Y. Cha and W. Choi, Nano Energy, 2018, 50, 733-743.

166 C. Hou, H. Wang, Q. Zhang, Y. Li and M. Zhu, Adv. Mater., 2014, 26, 5018-5024.

167 Y. J. Kim, H. M. Gu, C. S. Kim, H. Choi, G. Lee, S. Kim, K. K. Yi, S. G. Lee and B. J. Cho, Energy, 2018, 162, 526-533.

168 H. Wu, X. Liu, P. Wei, H.-Y. Zhou, X. Mu, D.-Q. He, W.-T. Zhu, X.-L. Nie, W.-Y. Zhao and Q.-J. Zhang, J. Electron. Mater., 2017, 46, 2950-2957. 